\title{
Formic acid production via methane peroxide oxidation over oxalic acid activated Fe-MFI catalysts
}

Oxana P. Taran ${ }^{1,2,3,}$, Svetlana A. Yashnik ${ }^{1}$, Vadim V. Boltenkov ${ }^{1}$, Ekaterina V. Parkhomchuk ${ }^{1}$, Kseniya A. Sashkina ${ }^{1}$, Artemiy B. Ayusheev ${ }^{1}$, Dmitrii E. Babushkin ${ }^{1}$, Valentin N. Parmon ${ }^{1}$

${ }^{1}$ Boreskov Institute of Catalysis SB RAS, Akad. Lavrentiev av., 5, Novosibirsk, 630090, Russia

${ }^{2}$ Institute of Chemistry and Chemical Technology $S B$ RAS, FRC KSC SB RAS Akademgorodok st., 50/24, Krasnoyarsk, 660036, Russia

${ }^{3}$ Siberian Federal University, Svobodny av., 79, Krasnoyarsk, 660041, Russia

* corresponding author: oxanap@catalysis.ru

\section{Abstract}

The process of synthesis of formic acid via partial peroxide oxidation of methane over Fe-MFI zeolites, as well as the influence of the catalyst activation by oxalic acid on the process parameters (conversion and selectivity) was studied. XRD, ICP-OES, SEM, UV-vis DR, ESR, $\mathrm{NH}_{3}-\mathrm{TPD},{ }^{27} \mathrm{Al}$ MAS NMR, $\mathrm{N}_{2}$ adsorption techniques were used for the catalyst characterization. The observed increase in TOF, selectivity to formic acid and efficiency of $\mathrm{H}_{2} \mathrm{O}_{2}$ utilization upon the catalyst activation with oxalic acid was accounted for by the formation of oligomeric oxo-clusters of Fe-ions and by an increase in the total acidity of the catalysts. The process of oxidation of main intermediates of the reaction, such as methanol and formic acid, was studied in the presence and in the absence of methane that allowed the mechanism of methane oxidation to formic acid to be suggested.

\section{Keywords}

Methane, Formic acid, Methanol, Peroxide oxidation, Fe-ZSM-5, Oxalic acid 


\section{Introduction}

Formic acid is a high-demand product for the chemical, textile, leather, pharmaceutical, agricultural, etc. industries due to its lower corrosivity as compared to inorganic acids. As a result, formic acid can substitute for inorganic acids in chemical processes [1]. On the other hand, formic acid is readily decomposed under controlled conditions of dehydrogenation to $\mathrm{H}_{2}$ and $\mathrm{CO}_{2}$ and dehydration to $\mathrm{CO}$ and $\mathrm{H}_{2} \mathrm{O}$; hence, it may be a promising material for storage of hydrogen [2-4] and CO [1]. Decomposition of formic acid to produce CO proceeds over strong acid catalysts [5-7] including zeolites [6]. It also is supposed [1] that formic acid can be used as a hydrogen donor instead of molecular hydrogen for hydrogenation and deoxygenation of organic constituents of biomass in order to synthesize ecologically friendly fuel.

Methane is one of the most promising sources of formic acid. Abundant resources of methane on our planet and a possibility of its continuous recovery as a result of the global nature's cycle of carbon (ca. $10^{9}$ ton per year) make it very attractive for solving numerous of energetic, resource and ecological problems [8]. However, methane molecules are chemically very inert, the dissociation energy of the $\mathrm{C}-\mathrm{H}$ bond being equal to $440 \mathrm{~kJ} \mathrm{~mol}^{-1}$ [9]. Thus, the chemical activation of methane is a fundamental problem of vital importance [10] and the development of a direct low temperature process for oxidation of methane to methanol $[11,12]$ and formic acid [1, 13-15] continues to be an urgent problem for modern catalysis. The known methods of methane hydroxylation to methanol by oxidation with $\mathrm{O}_{2}$ and $\mathrm{N}_{2} \mathrm{O}$, even when catalytic, still need high temperature and pressure [16-22]. Selective methods for synthesis of formic acid are based on hydrogenation of carbon dioxide in the presence of noble and transition metals $[2,23,24]$ and on selective oxidation of methanol $[25,26]$ achieve; these are, usually, high pressure and temperature two-stage processes. Therefore, the catalytic peroxide oxidation of methane under mild conditions may be one alternative to the direct catalytic valorization of methane for resolving the problem [27-31]. The process is aimed preferably at the oxidation of methane to methanol, while formic acid but not methanol often is the main reaction product during the peroxide oxidation of methane.

The available approaches to the catalytic valorization of methane are discussed in detail in a review paper by Olivos-Suarez et al. [31] these are high- and low-temperature processes using various catalysts and oxidants to obtain a wide latitude of products. The authors rely on earlier papers by Shilov et al. [32] and Coperet et al. [33] to distinguish three types of the C-H bond activation: true activation (occurs on the metal), false activation (occur on ligands surrounding the metal) and the Fenton activation. The false activation of the $\mathrm{C}-\mathrm{H}$ bond is characteristic of the peroxide oxidation of methane. The authors emphasize that the large-scale 
1 direct valorization of methane is unfeasible now but indicate main areas of most importance.

2 First, regarding the materials, more specific and accurate methods should be developed for 3 designing and synthesis of catalysts with required properties. Second, mechanistically, it is critically important to develop models for deeper insight into the catalytic functionalization of methane, and emphasis should be given to the studies of the mechanisms of oxidant activation and regeneration of the active site.

Simultaneously, it is known that natural enzymes of the methanemonooxygenase family which comprise iron or copper clusters are effective to produce methanol under mild conditions using methane as the substrate. On the other hand, $\mathrm{Fe}$ - and $\mathrm{Cu}$-containing zeolites are known as very active and stable catalysts for the wet peroxide oxidation (WPO) of a variety of organic compounds [34-40], and for gas phase methane oxidation [41, 42]. Even though $\mathrm{Fe}-$ and $\mathrm{Cu}-$ containing hydroxides and zeolites were shown earlier to catalyze the peroxide oxidation of light paraffins and olefins [43, 44], and, recently, of methane to methanol and/or formic acid at a high enough selectivity under mild conditions (323 K) [12, 45, 46], we failed to find any literature data concerning influence of structural and textural characteristics of the zeolite catalysts on the process selectivity. In our earlier paper [14] we considered the influence of the texture and morphology of Fe-containing zeolites on the selectivity and activity to the peroxide oxidation of methane. We supposed that the large external surface area of the zeolite catalyst characteristic of the nano- and microsize zeolites with the MFI structure decelerates the formation of methanol by the free radical mechanism. The structure of the active site responsible for the formation of products of the methane partial oxidation was actively discussed. For example, it was reported $[12,45,46]$, that the extraframework Fe-oxide species comprise most likely binuclear active site. $\mathrm{Fe}_{2} \mathrm{O}_{3}$ was reported to catalyze the deep oxidation of $\mathrm{CH}_{4}$. It was also proven that Brønsted acidity and confinement effects without the Fe sites are not capable of catalyzing the reaction. On the other hand, Shubin at. al. [47] consider forenuclear active centre $\mathrm{Fe}_{4} \mathrm{O}_{4}(\mathrm{OH})_{4}$.

The present study was aimed at comprehensive studies of the influence of some Fe-ZSM5 zeolites properties, such as their morphology (the crystallite size and texture properties) and structure of Fe-containing species inside the zeolite framework, on the hydrogen peroxide activation and its decomposition rate as well as the selectivity to partial peroxide oxidation of methane to formic acid. The catalysts of different morphology (nanosize, microsize, and bulky) were studied before and after activation of the catalytically active sites with an oxalic acid solution. The activation ensures the transformation of the iron cation oxygen surrounding from tetrahedral framework to octahedral extraframework oxygen surrounding that was supported by UV-vis DR, ESR, $\mathrm{NH}_{3}-\mathrm{TPD},{ }^{27} \mathrm{Al} \mathrm{NMR}$ studies [48]. In addition, there was an attempt of 
1 detailed studies of the influence of methanol and formic acid intermediates on the conversion

2 and selectivity of the peroxide oxidation of methane.

\section{Experimental}

\subsection{Chemicals and materials}

Tetrapropylammonium hydroxide (TPAOH, 25 wt. \% solution in water, Acros), tetrapropylammonium bromide (TPABr, $98 \%$, Aldrich), tetraethylorthosilicate (TEOS, $\geq 98 \%$, Angara-reactive, silica (fumed, $\geq 99 \%$, Aldrich), ethanol (95\%, Pharmaceya) and $\mathrm{Fe}\left(\mathrm{NO}_{3}\right)_{3} \cdot 9 \mathrm{H}_{2} \mathrm{O}\left(\geq 99 \%\right.$, Merck) were used for catalysts preparation. Oxalic acid $\left(\mathrm{H}_{2} \mathrm{C}_{2} \mathrm{O}_{4} \cdot 2 \mathrm{H}_{2} \mathrm{O}\right.$, Reakhim) was used for activating the catalysts. We also used hydrogen peroxide (30\%, Khimreaktivov), $\mathrm{CH}_{4}$ (99.9 \%, Moscow Gas Refinery Plant), $\mathrm{TiCl}_{4}$ (special purity grade Kristall Co.) and $\mathrm{LiClO}_{4} \cdot 3 \mathrm{H}_{2} \mathrm{O}$ (chemical purity grade). Milli-Q water (Millipore, France) was used for preparing all the solutions.

\subsection{Catalysts preparation}

Fe-silicalite Nanocrystals (sample "Nanocrystals") were synthesized as follows: $120 \mathrm{ml}$ of TEOS diluted with $120 \mathrm{ml}$ of ethanol was added at once to $240 \mathrm{ml}$ of TPAOH (12.5 wt. \%) under vigorous stirring for $20 \mathrm{~min}$, then $2.6 \mathrm{~g}$ of $\mathrm{Fe}\left(\mathrm{NO}_{3}\right)_{3} \cdot 9 \mathrm{H}_{2} \mathrm{O}$ dissolved in $5 \mathrm{ml}$ of distilled water was added dropwise. After stirring for $20 \mathrm{~min}$, the resultant clear light-yellow gel with $1.00 \mathrm{SiO}_{2}: 0.28$ TPAOH : $0.006 \mathrm{Fe}_{2} \mathrm{O}_{3}: 4.79 \mathrm{EtOH}: 1.75 \mathrm{H}_{2} \mathrm{O}$ molar composition was loaded in Teflon-lined stainless steel autoclaves and subjected to hydrothermal treatment in an oven at $363 \mathrm{~K}$ for 7 days. The produced milky Fe-silicalite suspension was purified in a series of three steps consisting of centrifuging for $5 \mathrm{~h}$ at relative acceleration of $3000 \mathrm{~g}$, followed by removal of the mother liquor and redispersion in distilled water under ultrasonification. The purified Fesilicalite was separated by centrifuging, dried at $323 \mathrm{~K}$ for $12 \mathrm{~h}$.

Large Fe-silicalite Microcrystals (sample "Microcrystals") were synthesized using a precursor solution with the chemical composition: $1.00 \mathrm{SiO}_{2}: 0.1 \mathrm{Na}_{2} \mathrm{O}: 0.11 \mathrm{TPABr}$ : $0.006 \mathrm{Fe}_{2} \mathrm{O}_{3}: 25 \mathrm{H}_{2} \mathrm{O}$. The synthesis procedure was typically as follows: $40 \mathrm{~g}$ of silica was gradually added to an aqueous solution containing $5.36 \mathrm{~g} \mathrm{NaOH}$ and $19.5 \mathrm{~g}$ of TPABr under magnetic stirring at ambient temperature. After stirring for $15 \mathrm{~min}, 3.2 \mathrm{~g}$ of $\mathrm{Fe}\left(\mathrm{NO}_{3}\right)_{3} \cdot 9 \mathrm{H}_{2} \mathrm{O}$ dissolved in $5 \mathrm{ml}$ of distilled water was added dropwise to obtain a milky suspension. After further stirring for $10 \mathrm{~min}$, the gel mixture was transferred to a Teflon-lined stainless steel autoclave. The autoclave was maintained in an oven at $433 \mathrm{~K}$ for $72 \mathrm{~h}$. After the hydrothermal treatment, the solid product was filtered, rinsed with distilled water and dried at $373 \mathrm{~K}$ for $12 \mathrm{~h}$. 
Commercial sample H-ZSM-5 with Si/Al ratio (zeolites module) equal to 30 (sample "Commercial") was manufactured by the Novosibirsk Chemical Concentrates Plant

3 (Novosibirsk, Russia). This zeolite sample was characterized earlier [49], and represents the 4 well-crystallized zeolite with the crystallinity degree no less than $95 \%$. ${ }^{27} \mathrm{Al}$ NMR data indicated the absence of extra-lattice $\mathrm{Al}^{3+}$ ions in the samples. The initial Fe content in the manufactured sample was $0.65 \mathrm{wt} \%$; the $\mathrm{Fe}^{3+}$ cations were predominantly stabilized as individual ions in tetrahedral positions of the zeolite lattice $\left(\mathrm{Fe}^{3+} \mathrm{Td}\right)[49]$.

All catalysts were calcined at $773 \mathrm{~K}$ for $5 \mathrm{~h}$. A part of the calcined samples was activated by oxalic acid as follows. Powders of the calcined catalysts were added to $1 \mathrm{M}$ aqueous solution of oxalic acid at the concentration of $100 \mathrm{~g} \cdot \mathrm{L}^{-1}$ and stirred for $30 \mathrm{~min}$ at $323 \mathrm{~K}$. The samples were then filtered and rinsed with distilled water until $\mathrm{pH}=7.0$, dried in air at $323 \mathrm{~K}$ for $12 \mathrm{~h}$ and calcined at $773 \mathrm{~K}$ for $3 \mathrm{~h}$. Then Fe-silicalite powders were ground in a ceramic mortar, and the fractions $<200 \mu \mathrm{m}$ were separated by sifting. The synthesized samples were "Nanocrystals activated”, "Microcrystals activated", "Commercial activated”, respectively (Table 1).

\subsection{Catalysts characterization}

Powder X-ray diffraction (XRD) patterns were acquired using a Siemens D500 diffractometer equipped with a $\mathrm{Cu} K \alpha$ radiation $(\lambda=0.154 \mathrm{~nm})$. The hydrodynamic diameters of zeolite particles in suspensions were measured by laser diffraction with a Malvern Zetasizer Nano. optical emission spectrometry (ICP-OES) with an Optima 4300 DV (PerkinElmer Inc., USA).

Chemical composition of the samples was determined by inductively coupled plasma

Scanning electron microscopy (SEM) images were acquired with a JEOL JSM-6460LV microscope at an operating voltage of $15-20 \mathrm{kV}$ and transmission electron microscopy (TEM) images were obtained by a JEOL JEM-2010 microscope operating at $200 \mathrm{kV}$.

Nitrogen adsorption-desorption isotherms were measured with a Quantachrome Autosorb-6B-Kr surface area analyzer at $77 \mathrm{~K}$. Prior to analysis, the samples were degassed at $573 \mathrm{~K}$ for $10 \mathrm{~h}$. Specific surface areas were determined applying the BET equation [50]. Pore size distributions were estimated by the BJH method [51]. Micropore volumes and external surface areas were also calculated by $\alpha$-method using $\mathrm{N}_{2}$ adsorption isotherms on the reference LiChrospher Si-1000 silica gel, reported in literature [52, 53].

The ${ }^{27} \mathrm{Al}$ MAS NMR experiments for the samples under study were performed on a Bruker Avance 400 NMR pulse spectrometer using a commercial 4-mm MAS probehead. The 
$1 \mathrm{pi} / 12$ single pulse was used to obtain the MAS spectra. The recycle delay was $1 \mathrm{~s}$ for 6000 scans.

2 The NMR spectra were referenced to the $\mathrm{Al}(\mathrm{OH})_{6}$.

The acidities of the samples were measured by TPD of ammonia in using lab-scale calibrated equipment. Ammonia quantity signal was measured by the quadrupole mass spectrometer HiCube RGA100 and temperature control was operated by temperature controller Termodat 13KT2/5T supplying continuous sample heat rate.

UV-vis diffuse reflection (DR) spectra were recorded using a Shimadzu UV-2501 PC at the wavenumber range $11000-54000 \mathrm{~cm}^{-1}$ at $298 \mathrm{~K}$.

ESR spectra of the samples were recorded on a Bruker EMX EPR spectrometer with microwave region $\lambda=3 \mathrm{~cm}$, high-frequency modulation of magnetic field $100 \mathrm{kHz}$, and magnetic field up to $5000 \mathrm{G}$ at 77 and $300 \mathrm{~K}$ in a quartz glass ampoule with the internal diameter of $3 \mathrm{~mm}$. Parameters of the ESR spectra were determined by a comparison with the spectrum of diphenylpicrylhydrazyl (DPPH, $g=2.0037 \pm 0.0002)$.

\subsection{Catalysts testing}

Catalytic oxidation of methane was carried out using a $450 \mathrm{~mL}$ autoclave made of Hastelloy (AMAR, India) under vigorous stirring (1500 rpm) using a magnetically driven propeller mixer. In a typical experiment, $1 \mathrm{M}$ solution of $\mathrm{H}_{2} \mathrm{O}_{2}(80 \mathrm{~mL})$ was placed in the reactor. The reactor was sealed, purged 5 times with methane at $10 \mathrm{bar}$, stirred, gas phase was evacuated every time. Methane pressure was increased to $30 \mathrm{bar}$, and heating was started. The autoclave was heated to the desired reaction temperature of $323 \mathrm{~K}$. Once the reaction temperature was attained, a catalyst $(216 \mathrm{mg})$ was loaded into the reactor through the ball valve for powder inlet. The system was pressurized with methane to a fixed pressure (30 bar), the solution was vigorously stirred at $1500 \mathrm{rpm}$ and maintained at the reaction temperature for a fixed period of time (10-30 $\mathrm{min})$. When the reaction was over, the reaction gas was drawn for analysis in a gas sampling system. The reaction mixture was filtered using a cellulose acetate syringe filter with $0.45 \mu \mathrm{m}$ pores and analyzed by GLC, HPLC and ${ }^{1} \mathrm{H}$ and ${ }^{13} \mathrm{C}$ NMR.

A blank experiment was carried out similar way but without a catalyst.

In a leaching test experiment, the solution obtained after methane oxidation over the Commercial activated catalyst was used. Additional amount of hydrogen peroxide was added to the solution to reach the concentration of $1 \mathrm{M} \mathrm{H}_{2} \mathrm{O}_{2}$. The reaction was conducted usual way.

In the reaction with the $\mathrm{Fe}\left(\mathrm{NO}_{3}\right)_{3}$ solution, the salt concentration $(0.31 \mathrm{mM})$ was chosen to attain the quantity of $\mathrm{Fe}$ equivalent to the quantity introduced into the solution with the Commercial catalyst. 
Methanol and formic acid were oxidized in the atmosphere of either argon or methane the way similar to the methane oxidation. The initial concentrations of methanol and formic acid were $50 \mathrm{mmol} \mathrm{L}{ }^{-1}$. The reactions were carried out using a batch glass reactor under continuous stirring for a fixed period of time (30 min).

In the leaching test experiment, the solution obtained after methanol oxidation in argon over the Commercial activated catalyst was used. The solution was filtered using a cellulose acetate syringe filter and allowed to stay at room temperature for 24 hours. Concentrations of hydrogen peroxide, methanol and formic acid were measured. Methanol and hydrogen peroxide were added to the solution to attain the concentrations: for the methanol-1M; for the $\mathrm{H}_{2} \mathrm{O}_{2}-50$ $\mathrm{mmol} \cdot \mathrm{L}^{-1}$.

A formal TOF of the catalysts in the methane oxidation (in respect to the amount of iron present in the sample) and in the hydrogen peroxide consumption were estimated using a total amount of all the detected products and a total amount of decomposed $\mathrm{H}_{2} \mathrm{O}_{2}$ by the following formulas: defined only when the mechanism of the catalyst operation will be known.

Selectivity for individual products was estimated by the following formula:

where $v(\mathrm{CO}), v\left(\mathrm{CO}_{2}\right), v\left(\mathrm{CH}_{3} \mathrm{OH}\right), v(\mathrm{CHOOH})$ are molar quantities of $\mathrm{CO}, \mathrm{CO}_{2}, \mathrm{CH}_{3} \mathrm{OH}$, and $\mathrm{CHOOH}$ formed during the reaction, respectively, $v\left(\mathrm{H}_{2} \mathrm{O}_{2}\right)$ is the molar quantity of decomposed hydrogen peroxide, $v(\mathrm{Fe})$ is the molar quantity of iron in the catalyst, $t$ (reaction) is the reaction time equal to $0.5 \mathrm{~h}$. Indeed, this value is a lower limit of real TOF which should characterize only the catalyst active sites; unfortunately, the concentration of such sites can be

$$
\text { Selectivit } y\left(\text { product }_{x}\right)=\frac{v\left(\text { product }_{x}\right)}{\sum v(\text { products })} \times 100 \%
$$

where: $v\left(\right.$ product $\left._{\mathrm{x}}\right)$ are molar quantities of $\mathrm{CO}, \mathrm{CO}_{2}, \mathrm{CH}_{3} \mathrm{OH}$, and $\mathrm{CHOOH}$ formed during the reaction, respectively, $\Sigma v$ (products) is a sum of the molar quantities of all mentioned products.

\section{5. $\mathrm{H}_{2} \mathrm{O}_{2}$ decomposition}

$\mathrm{Fe}-$ silicalite catalysts were tested also in the $\mathrm{H}_{2} \mathrm{O}_{2}$ decomposition in a $5 \mathrm{ml}$ thermostated glass batch reactor agitated with a magnetic stirrer. Kinetic curves of the $\mathrm{O}_{2}$ emission were recorded by a barometric instrument. Reaction conditions: volume (V) $2.5 \mathrm{ml}$, the catalyst 
1 concentration $20 \mathrm{~g} \cdot \mathrm{L}^{-1}, 298-323 \mathrm{~K}$, the initial concentration of $\mathrm{H}_{2} \mathrm{O}_{2} 1 \mathrm{M}$. Reaction was carried 2 out to complete conversion of hydrogen peroxide. The reaction time ranged from 15 min over 3 Microcrystal activated at $333 \mathrm{~K}$ to $380 \mathrm{~min}$ over Microcrystals at $298 \mathrm{~K}$. The first order reaction rate constant $(\mathrm{k})$ was determined from the straight-line anamorphous in the first order coordinates. The apparent activation energy $\left(E_{a}\right)$ was calculated from Arrhenius plot. A TOF of the catalysts in the hydrogen peroxide decomposition were calculated by the following formula:

$$
\operatorname{TOF}\left(\mathrm{H}_{2} \mathrm{O}_{2}\right)=\frac{\mathrm{C}_{0}\left(\mathrm{H}_{2} \mathrm{O}_{2}\right) \cdot k \cdot V}{v(\mathrm{Fe})}
$$

\subsection{Analytic methods}

The gas phase composition was analyzed using a gas chromatograph Kristall 2000M (from Chromatec, Russia) equipped with a flame ionization detector and a methanator. The column was $2 \mathrm{~m} \times 2 \mathrm{~mm}$, filled with Chromosorb 102, argon as the gas carrier.

The liquid phase composition was analyzed by two methods. Methanol was detected using a gas chromatograph Kristall 2000M equipped with a flame ionization detector and a chromatographic column EQUITY ${ }^{\mathrm{TM}}-5$ (from Supelco), $30 \mathrm{~m} \times 0.32 \mathrm{~mm} \times 0.25 \mu \mathrm{m}($ film thickness), argon as gas carrier. The concentration of formic acid was determined using a liquid chromatograph Milikhrom A02 (from Institute of Chromatography "EcoNova", Russia) equipped with a spectrometric detector $(\lambda=210 \mathrm{~nm})$, an ion exchange column Diaspher-250PA, 2 $\mathrm{mm} \times 75 \mathrm{~mm}$. Eluents: $0.04 \mathrm{M} \mathrm{LiClO}_{4}$ aqueous solution and $\mathrm{H}_{2} \mathrm{O}$; flow rate $0.2 \mathrm{~mL} \cdot \mathrm{min}^{-1}$.

${ }^{1} \mathrm{H}$ and ${ }^{13} \mathrm{C}$ NMR spectra of the reaction product solutions were recorded on Bruker AVANCE-400 spectrometer in standard $5 \mathrm{~mm}$ NMR tubes without dilution with $\mathrm{D}_{2} \mathrm{O}$ (consequently, no field lock applied), at $400.13 \mathrm{MHz}\left({ }^{1} \mathrm{H}\right)$ and $100.61 \mathrm{MHz}\left({ }^{13} \mathrm{C}\right)$. For ${ }^{13} \mathrm{C} \mathrm{DEPT}$ (Distortionless enhancement by polarization transfer) spectra the following parameters were used: $90^{\circ}$ pulse length of $7 \mu \mathrm{s}\left({ }^{13} \mathrm{C}\right)$ and $14 \mu \mathrm{s}\left({ }^{1} \mathrm{H}\right)$, spectral width $25 \mathrm{KHz}, \Delta=3.38 \mathrm{~ms}$ (optimal for ${ }^{1} \mathrm{~J}_{\mathrm{CH}}=148 \mathrm{~Hz}$ ), 65536 complex data points in the time domain, acquisition time $1.31 \mathrm{~s}$ and relaxation delay $5 \mathrm{~s}$ with 8192 scans collected. For quantitative analysis with internal reference ${ }^{1} \mathrm{H}$ NMR spectra were recorded at $298-310 \mathrm{~K}$ using short $1 \mu \mathrm{s}\left(\approx 7^{\circ}\right)$ pulses and long relaxation delay between scans $(8 \mathrm{~s})$, spectral width $8 \mathrm{KHz}, 168$ scans; and processed with an optimal exponential multiplication factor $(0.3 \mathrm{~Hz})$ with zero data filling to 65536 points. Measured amount of 1,4-dioxane was added to the sample prior to NMR analysis and the integral intensity of its signal ( $8 \mathrm{H}$ atoms) was used as a quantitative reference. Separate experiments proved that there wasn't any other signal at or near its chemical shift (taken as a reference: ${ }^{1} \mathrm{H} 3.75 \mathrm{ppm},{ }^{13} \mathrm{C}$ $67.19 \mathrm{ppm}$ ) and that further increasing of the relaxation delay over $8 \mathrm{~s}$ had no effect on the signal intensities. 


\subsection{Catalysts characterization}

Chemical composition and textural properties of the Nanocrystals and Microcrystals as well as the Commercial H-ZSM-5 catalysts are discussed elsewhere ([54] and [49], respectively). These properties of the sample activated with oxalic acid were considered in detail elsewhere [14]. In the initial catalysts, the iron content was varied from $1.42 \mathrm{wt} \%$ (Fe-silicalites) to $0.65 \mathrm{wt}$ $\%$ (Commercial H-ZSM-5). The process of the catalyst activation does not follow in a significant

8 leaching of the active component. The maximal Fe loss was observed only with Nanocrystals 9 (9.1\%).

Large BET total surface areas (398-524 $\left.\mathrm{m}^{2} \mathrm{~g}^{-1}\right)$ were characteristic of the initial catalysts (Table 1), and large external surface areas were typical of Nanocrystals and Microcrystals. The large total pore volume of Nanocrystals was the result of the extended mesoporosity of the particles. A sharp maximum was seen at $28 \mathrm{~nm}$ in the distribution curves of the Fe-silicalite Nanocrystals to argue for the close packing of particles in the bulk of the material. Some number of mesopores of 10-20 nm in the size in the Fe-silicalite Microcrystals and Commercial sample seemed to be the structural defects.

The treatment with oxalic acid resulted in a significant decrease in $\mathrm{S}_{\mathrm{BET}}$ and external surface area in Nanocrystals and Commercial catalysts. A slight decrease in the micropore volume with simultaneous enlargement of mesopores, probably due to partial dissolution of silica and iron, was observed in Nanocrystals. On the contrary, some increase in the micro- and mesopore volumes and, therefore, an increase in $\mathrm{S}_{\mathrm{BET}}$ were observed in Microcrystals. For the Commercial zeolite, the microporosity and mesopore volume decreased to cause $\mathrm{S}_{\mathrm{BET}}$ and $\mathrm{S}_{\mathrm{ex}}$ shrinkage due to removal of the extraframework aluminum complex from the external surface of the zeolite crystals or extraction of iron ions from the framework to extraframework position. The different effect of the activation procedure on the textural and catalytic performances can be accounted for by different initial state of iron in Nanocrystal, Microcrystal and Commercial catalysts.

The laser diffraction and transmission electron microscopic studies revealed a narrow size distribution and an average size of $180 \mathrm{~nm}$ and spheroidal shape of the Fe-silicalite nanocrystals [55] but showed a wide size distribution (2 to $10 \mu \mathrm{m}$ ) in Fe-silicalite Microcrystals. Aggregates of closely packed crystals were mainly formed both in the Fe-silicalite Nanocrystals and Microcrystals after centrifuging followed by drying and calcination, the single crystals also being 
1 crystals with different shapes and sizes gave the main contribution to the specific weight of the

2 Commercial sample.

XRD patterns of the all Fe-silicalites and Commercial catalyst are typical of the MFI structure with a high crystallinity (Fig. 2). The sample activation with oxalic acid followed by the calcination resulted in a small decrease in the crystallinity due to the formation of defects induced by the migration of metal cations $\left(\mathrm{Fe}^{3+}\right.$ and $\left.\mathrm{Al}^{3+}\right)$ from the framework positions and partial dissolution of their matrices. A decrease in the intensity of the lines at $2 \theta$ range of 22 to $25^{\circ}$ may indicate filling the zeolite channels with extraframework iron and/or aluminium oxide complexes that may be a reason for decreasing micropore volume in the activated Nanocrystals Fe-silicalite and Commercial zeolite.

In order to check the possibility of extracting $\mathrm{Al}^{3+}$ ions from their positions in the zeolite structure, the state of aluminium ions in the Commercial and Commercial activated catalysts was studied using ${ }^{27} \mathrm{Al}$ MAS NMR technique (Fig. 3). In the spectra of the initial and activated zeolite, there is observed an intense signal at $55 \mathrm{ppm}$ characteristic of aluminium ions in tetrahedral environment of oxygen ligands $\left(\mathrm{AlO}_{4}\right)$ and a less intense signal at 0 ppm assigned aluminium ions in octahedral environment of oxygen ligands $\left(\mathrm{AlO}_{6}\right)$. Intensities of signals of $\mathrm{AlO}_{4}$ and $\mathrm{AlO}_{6}$ are identical in ${ }^{27} \mathrm{Al}$ MAS NMR spectra of the activated and non-Commercial activated catalysts. The following can be concluded: (1) $\mathrm{Al}^{3+}$ ions are stable in the zeolite lattice during the treatment with oxalic acid and (2) changes in the XRD patterns of the Commercial activated catalyst is caused by the migration of $\mathrm{Fe}^{3+}$ but not $\mathrm{Al}^{3+}$ cations.

The state of iron species in the catalysts was studied by UV-visible DR (Fig. 4) and ESR (Fig. 5) spectroscopy. A strong absorption at the $30000-50000 \mathrm{~cm}^{-1}$ was observed with all the materials. Absorption bands at 41000 and $46000 \mathrm{~cm}^{-1}$ relate to $\mathrm{O}^{2-}$ ligand $\rightarrow$ metal charge transfer involving $\mathrm{Fe}^{3+}$ in the octahedral $\left(\mathrm{Fe}^{3+} \mathrm{Oh}\right)$ and tetrahedral $\left(\mathrm{Fe}^{3+}{ }_{\mathrm{Td}}\right)$ oxygen surroundings. The absorption at $31000-33000 \mathrm{~cm}^{-1}$ in UV-visible DR spectra of initial and activated samples indicate the presence of $\mathrm{Fe}_{2} \mathrm{O}_{3}$-like aggregates with $\mathrm{Fe}^{3+}$ Oh ions in oxygen-containing surrounding, but the contribution of this fraction is impossible to measure by this method. A great difference in UV-visible DR spectra at $31000-33000 \mathrm{~cm}^{-1}$ was observed between the initial and activated Microcrystals (Fig. 4). Thus, the Microcrystals activation causes the significant iron species migration followed by the aggregation of iron-oxygen species.

An increasing intensity of a.b. at $41000-46000 \mathrm{~cm}^{-1}$ is an evidence of the formation of isolated $\mathrm{Fe}^{3+}$ ions with octahedral oxygen containing environment upon activation of the $\mathrm{Fe}-$ silicalite Nanocrystals and Commercial catalyst by the oxalic acid. The initial and activated Nanocrystals Fe-silicalite and Commercial catalysts also contain iron-oxygen olygomeric complexes or clusters of $\mathrm{Fe}^{3+}$ oh characterized by the d-d transition at $12000 \mathrm{~cm}^{-1}$ and $\mathrm{CTB} \mathrm{O} \mathrm{O}^{2-}$ - 
$1 \mathrm{Fe}^{3+}$ at 20000 and $25000-28000 \mathrm{~cm}^{-1}$ [56]. However, it is difficult to assess changes in the 2 concentration of the oligomeric complexes or clusters during the activation because of the low 3 extinction of the said a.b. Less intense bands at 23000, 25000, and $27000 \mathrm{~cm}^{-1}$ assigned to d-d

EPR spectra of initial samples Nanocrystals (Fig. 5a) and Microcrystals (Fig. 5b) Fe-MFI and Commercial H-ZSM-5-30 (Fig. 5c) were acquired at 300 and $77 \mathrm{~K}$. In the spectra, there is observed a narrow isotropic signal (g-factor equal to 4.3) and two broad asymmetric signals (ffactors equal to 1.99-2.0 and 2.3-2.6) of different widths. The first signal at the low-field region is assigned to isolated $\mathrm{Fe}^{3+}$ Td ions coordinated tetrahedrally to oxygen-containing ligands of the zeolite lattice $\left({ }^{6} \mathrm{~S}\right.$-ground state, $\left.\mathrm{S}=5 / 2\right)[58,59]$. The signal with $\mathrm{g}=8.1$ of isolated $\mathrm{Fe}^{3+}$ ions with higher than tetrahedral coordination is observed in the spectra of neither initial nor activated zeolites [58, 59]. The signal with the line semiwidth of ca. 400-600 $\mathrm{G}$ and $\mathrm{g}_{\mathrm{ef}}=1.99-2.0$ is assigned to interacting $\mathrm{Fe}^{3+}$ ions to form ion pairs (dimmers) or small clusters with common oxygen-containing ligands. These are antiferromagnetic clusters because the temperature dependence of signal; intensity obeys Curie's Law. The broader signal with the line semiwidth of ca $1200-1500 \mathrm{G}\left(\mathrm{g}_{\mathrm{ef}}=2.3-2.6\right)$ relates to $\mathrm{Fe}^{3+}$ oh with strong interaction in superparamagnetic particles similar to $\alpha-\mathrm{Fe}_{2} \mathrm{O}_{3}$ in structure. $\alpha-\mathrm{Fe}_{2} \mathrm{O}_{3}$ are ferromagnetic particles: Their signals are more intense at $300 \mathrm{~K}$ than at $77 \mathrm{~K}$ that does not meet Curie's Law. An increase of the ferromagnetic particles in size may favor the positive exchange interaction between $\mathrm{Fe}^{3+}$ ions and, hence, result in the signal broadening and shifting of G-factor towards 3.7. This is what we observed sometimes eith the Commercial H-ZSM-5-30 sample.

Thus, the following states of $\mathrm{Fe}^{3+}$ ions were identified by EPR in all the catalysts: 1) isolated $\mathrm{Fe}^{3+}$ Td ions in tetrahedral coordination; 2) binuclear and/or oligomeric oxo-clusters of $\mathrm{Fe}^{3+}$ Oh-ions in octahedral coordination of oxygen-containing ligands; 3) $\alpha-\mathrm{Fe}_{2} \mathrm{O}_{3}$ nanoparticles. Even though the concentration of iron ions is considerably higher in Nanocrystals and Microcrystals Fe-silicalites than in Commercial H-ZSM-5, comparable numbers of tetrahedral $\mathrm{Fe}^{3+} \mathrm{Td}$ ions were observed in all these catalysts. The maximal concentration of binuclear and/or oligomeric oxo-clusters of $\mathrm{Fe}^{3+} \mathrm{Oh}^{-}$ions was observed in the sample of Microcrystals Fe-silicalite. In the activated samples, the concentrations of various states of $\mathrm{Fe}^{3+}$ ions depended on the zeolite topology. With all the catalysts, the trend to decreasing the concentration of isolated $\mathrm{Fe}^{3+} \mathrm{Td}$ ions and to increasing the concentrations of binuclear and/or oligomeric oxo-clusters of $\mathrm{Fe}^{3+} \mathrm{Oh}^{-}$ions 
1 was observed after treatment with oxalic acid. However, EPR data on Microcrystals indicate a 2 decrease of $\alpha-\mathrm{Fe}_{2} \mathrm{O}_{3}$ particles in size.

Temperature programmed desorption (TPD) of ammonia was used to characterize acidity of the materials (Fig. 6), the results obtained were discussed in detail elsewhere [14]. A low temperature peak (l-peak) at ca. $430 \mathrm{~K}$ is observed in the ammonia TPD spectra of all the samples under study, and a shoulder at $520 \mathrm{~K}$ which is more apparent for the Commercial catalyst. The 1-peaks correspond to ammonia adsorbed on terminal OH-groups [60], and Lewis acid sites [61]. In addition, high temperature peaks (h-peaks), which usually are assigned to strong acid sites of Brönsted nature [62, 63], are observed in the spectra of the Fe-silicalite Nanocrystals and Commercial catalyst.

In the case of the Fe-silicalite Nanocrystals, high temperature peaks (h-peaks) shift from 700 to $645 \mathrm{~K}$ after the activation to indicate weakening of the strength of acid sites, seemingly, due to partial iron leaching. In the TPD profile of Fe-silicalite Microcrystals, no h-peak but a long shoulder, which is assumed to be the superposition of peaks referring to acid sites with the different strength, is observed. A high temperature peak observed at $647 \mathrm{~K}$ in the TPD profiles of the activated Fe-silicalite Microcrystals is assigned to the extended mesoporosity and improved exposure of Brönsted acid sites to ammonia in the zeolite channels. The TPD profile of the Commercial zeolite is much different due to the presence of aluminum in the sample: There is an intense peak at $520 \mathrm{~K}$ along with the 1-peak and h-peak observed at high temperature of $720 \mathrm{~K}$ (Fig. 6). Upon the activation of the Commercial sample, the 1-peak at $520 \mathrm{~K}$ increases and the 1peak at $430 \mathrm{~K}$ decreases in intensity due to a change in the concentration of terminal OH-groups and the formation of Lewis acid sites. While h-peak does not shift to lower temperature after the activation, the acidity strength of Brönsted sites does not change. The total $\mathrm{NH}_{3}$ adsorption capacity of zeolites was calculated by integrating the area under the TPD profiles (Table 1). To sum up, the Commercial sample is more acidic than Fe-silicalites, the number of acid sites in the former being twice as high as that in the latter.

In the course of the peroxide oxidation of methane, there are at least two competing processes in the reaction medium, namely the peroxide oxidation of substrate and useless catalytic decomposition of hydrogen peroxide. Therefore, it is important to understand how the preparation procedure influences the catalyst activity to hydrogen peroxide decomposition and how the catalyst activation influences the kinetics of this decomposition.

In the blank run (without any catalyst), zero conversions of hydrogen peroxide were observed. Kinetic curves of the catalytic decomposition of hydrogen peroxide are linearized in 
1 the first order coordinates in respect to $\mathrm{H}_{2} \mathrm{O}_{2}$. Figs. $7 \mathrm{a}$ and $7 \mathrm{~b}$ show kinetic curves of the

2 decomposition of hydrogen peroxide and their linearization with the commercial activated catalyst as an example. Results of the kinetic experiments on decomposition of hydrogen peroxide [14] are summarized in Table 1. The first order rate constants and TOF at $323 \mathrm{~K}$ in the presence of fresh catalysts change in the series: Microcrystals $<$ Nanocrystals $<$ Commercial (Table 1, entry 1,3,5). After the activation with oxalic acid, the TOF of the hydrogen peroxide decomposition increases over all catalysts. In the case of Microcrystals weakly acidic catalytically active $\alpha-\mathrm{Fe}_{2} \mathrm{O}_{3}$-like clusters and additional mesopores are formed (see the $\mathrm{UV}$-vis DR (Fig. 4) and TPD-ammonia data (Fig. 6)) to favor the reactant diffusion and considerable increase in the rate constant The rate constant of the $\mathrm{H}_{2} \mathrm{O}_{2}$ decomposition over the Commercial catalyst increases by about a $30 \%$ after its activation owing to an increasing number of catalytically active sites such as oligomeric Fe oxide clusters. Only for Nanocrystals, the activation does not result in the reaction acceleration and rate constant increase, seemingly, because of leaching of ca. $9 \%$ of iron, but in some increase in TOF (Table 1).

The apparent activation energy $\left(\mathrm{E}_{\mathrm{a}}\right)$ of $\mathrm{H}_{2} \mathrm{O}_{2}$ decomposition for all the catalysts under study was determined by kinetic experiments at 303, 313, 323, $333 \mathrm{~K}$ (Table 1). With the Nanocrystals catalyst, $E_{a}$ equal to $70 \mathrm{~kJ} \cdot \mathrm{mol}^{-1}$ is an evidence of predominantly kinetic regime of the reaction since the activation energy of $\mathrm{H}_{2} \mathrm{O}_{2}$ decomposition in homogeneous iron salt solutions is estimated as $84 \pm 4 \mathrm{~kJ} \mathrm{~mol}^{-1}$ [64]. The activation energy of ca. $53 \mathrm{~kJ} \cdot \mathrm{mol}^{-1}$ over the Microcrystals indicates the increasing contribution of internal diffusion restrictions to the reaction rate due to significantly lower activation energy of the diffusion compared with the $\mathrm{H}_{2} \mathrm{O}_{2}$ decomposition. The activation energy increases considerably after the activation of Nanocrystals and Microcrystals as a result of declining the internal diffusion limitations. The activation energy over the Commercial catalyst is practically not changed upon the catalyst activation due to substantial diffusion limitations for the reaction in the sample. However, the diffusion limitation here is caused by the small external surface area of the crystallites (one fifth to one tenth of those over Nanocrystals and Microcrystals catalysts). In addition it has been shown earlier $[65,66]$, that oxygen bubbles generated during decomposition of $\mathrm{H}_{2} \mathrm{O}_{2}$ on the external surface of the crystallites hinders the access of the reactants to the catalytically active sites.

\subsection{Kinetics of the methane partial WPO over the activated Microcrystals catalyst}

Three individual experiments with contact times equal to 10,20 and 30 min were carried out in order to determine the optimal reaction time of partial oxidation of methane in the 
1 presence of the catalyst which is the most active for decomposition of hydrogen peroxide (the 2 Microcrystals activated).

$\mathrm{CO}$ and $\mathrm{CO}_{2}$ were detected as the products of the gas phase reaction. Methanol was detected by GC and formic acid by HPLC in the aqueous phase (Fig. 8). $\mathrm{CO}_{2}$ is continuously accumulated during the reaction. The liquid product concentrations are stabilized in 20 min when the rates of their accumulation and oxidation to carbon oxides become identical. While the Microcrystals activated catalyst is the most active in respect to the oxidant decomposition, the 30 min reaction time seems most appropriate.

By using ${ }^{1} \mathrm{H}$ and ${ }^{13} \mathrm{C}$ NMR the following main products were detected in the reaction solutions: methanol $\left({ }^{1} \mathrm{H}\right.$ : $\delta 3.35$ (s), ${ }^{13} \mathrm{C}$ DEPT: $\left.\delta 49.69\left(\mathrm{CH}_{3}\right)\right)$, formic acid $\left({ }^{1} \mathrm{H}: \delta 8.26(\mathrm{~s}),{ }^{13} \mathrm{C}\right.$ DEPT: $\delta 167.06(\mathrm{CH})$ ), formaldehyde hydrate as geminal methandiol $\mathrm{CH}_{2}(\mathrm{OH})_{2}\left({ }^{1} \mathrm{H}: \delta 5.04(\mathrm{~s})\right.$, ${ }^{13} \mathrm{C}$ DEPT: $\left.\delta 93.32\left(\mathrm{CH}_{2}\right)\right)$, and methyl hydroperoxide $\left({ }^{1} \mathrm{H}: \delta 3.86(\mathrm{~s}),{ }^{13} \mathrm{C}\right.$ DEPT: $\left.\delta 65.66\left(\mathrm{CH}_{3}\right)\right)$ (Fig. 8).

It should be noted that, for the ${ }^{13} \mathrm{C}$ chemical shifts of $\mathrm{C}-\mathrm{O}$ signal, alkyl hydroperoxides typically show a signal 12-16 ppm to the low field from corresponding alcohols. Thus, our assignment of the $\mathrm{CH}_{3}$ (quartet) signal at otherwise rather high chemical shift of $65.66 \mathrm{ppm}$ is explained. Quantitative ${ }^{1} \mathrm{H}$ NMR analysis illustrated by Fig. 9 provided the following molar \% (refers to a total of products in the liquid phase): methyl hydroperoxide $(6.0 \%)$, hydrated formaldehyde (16 $\pm 3 \%$, water signal hinders more precise determination), methanol (14.5\%) and formic acid $(63.0 \%)$. One of these products, namely formaldehyde hydrate, has its only signal in the vicinity of the solvent peak, so the accuracy of the analysis suffers in its case. Fortunately, its signal width is very much smaller than that of the water signal. This fact opens up a possibility to subtract water signal by the baseline correction of the corresponding region quite reproducibly. The insert in Fig. 9 shows formaldehyde hydrate ${ }^{1} \mathrm{H}$ NMR signal prior to such baseline correction. It must be noted, however, that the width of the water signal and its position in the spectrum depends on numerous factors such as the concentration of leached $\mathrm{Fe}^{3+}$, concentration of unprocessed $\mathrm{H}_{2} \mathrm{O}_{2}$ which the water protons are in exchange with (not always fast in NMR time scale as evidenced by observation of a separate $\mathrm{H}_{2} \mathrm{O}_{2}$ signal at $11 \mathrm{ppm}$ in the ${ }^{1} \mathrm{H}$ NMR spectrum of "H-ZSM-5" reaction system products) and so on. Consequently, the accuracy of formaldehyde hydrate analysis may differ. In the case of Fig. 9 spectrum, the accuracy was improved simply by increasing the temperature to $310 \mathrm{~K}$ in order to shift $\mathrm{H}_{2} \mathrm{O}$ signal to the higher field (it has a strong negative temperature coefficient of the chemical shift). Methylhydroperoxide is supposed elsewhere to intermediate of the methanol formation [12, 45, 67]. It is poorly stable to decomposition. Thus, the storing of a filtered reaction solution results in a decrease in the concentration of methyl hydroperoxide at a simultaneous increase in the 
1 concentration of methanol. Formaldehyde was only once detected in a similar system [67], the authors assumed its formation from organic ligands of the catalyst used.

\subsection{Peroxide oxidation of methane}

Table 2 shows results of the catalyst testing in the methane oxidation, for brief discussion on some of them see Ref. [14]. In the blank run (without any catalyst), zero conversions of methane and hydrogen peroxide were observed. This is an evidence of the absence of contribution of catalysis at the reactor walls to the process of peroxide oxidation of methane (Table 2, entry 7). The conversion of methane over Fe-containing catalysts was 0.14 to $1.02 \%$ (Table 2, entry 1-6). The treatment of all the catalysts with oxalic acid results in a noticeable improvement of their activity (compare the conversion and TOF values). The Commercial activated catalyst (Table 2, entry 6) appeared most active both to methane oxidation and to decomposition of hydrogen peroxide. The activation affects different ways of the oxidant conversion. The conversion of hydrogen peroxide increases by $5 \%$ and $4 \%$ upon activation of the Commercial (Table 2, entry 5-6) and Microcrystals catalysts (Table 2, entry 3-4), respectively. The activation of Nanocrystals (Table 2, entry 1-2) does not cause changes in the $\mathrm{H}_{2} \mathrm{O}_{2}$ conversion but TOF increases slightly. Similar effects were observed during the decomposition of hydrogen peroxide in the absence of methane. Notice however that the presence of the substrate decreases substantially the oxidant conversion and TOF values of its decomposition (with the exception of the initial Microcrystals due to the strong diffusion control). Therefore, it is reasonable to conclude that the same catalytically active sites take part, at least at the early stage, both in the decomposition of hydrogen peroxide (free radical mechanism in an acidic medium typically takes place) [68] and in oxidation of methane with hydrogen peroxide.

Note, the stoichiometric ratio for hydrogen peroxide and methane are following: for $\mathrm{CO}_{2}$ formation $-4: 1$; for $\mathrm{HCOOH}-3: 1$; for $\mathrm{CO}-2: 1$; for $\mathrm{CH}_{3} \mathrm{OH}-1: 1$. A ratio of catalyst activities for hydrogen peroxide consumption and methane oxygenation $\left(\mathrm{TOF}\left(\mathrm{H}_{2} \mathrm{O}_{2}\right) / \mathrm{TOF}\left(\mathrm{CH}_{4}\right)\right)$ for calcined catalysts varied from 16.2 for the Nanocrystals to 6.6 for the Commercial catalysts. For the activated catalysts a significant decrease of the $\operatorname{TOF}\left(\mathrm{H}_{2} \mathrm{O}_{2}\right) / \operatorname{TOF}\left(\mathrm{CH}_{4}\right)$ ratio was observed. However even for the Commercial activated catalyst this ratio (4.2) was about a third higher than the stoichiometric ratio for the formic acid formation. Hence a contribution of the free radical mechanism in $\mathrm{H}_{2} \mathrm{O}_{2}$ decomposition can be assumed. However, it is an optimistic fact that the proportion of hydrogen peroxide as high as ca. $75 \%$ is consumed for methane oxidation over the activated commercial catalyst and only the rest for the concurrent decomposition of hydrogen peroxide itself. Therefore, it seems quite realistic to synthesize iron-containing catalysts for 
preferential oxidation of light alkanes with $\mathrm{H}_{2} \mathrm{O}_{2}$ under mild conditions. In addition, there is the possibility of replacing more expensive of $\mathrm{H}_{2} \mathrm{O}_{2}$ by $\mathrm{O}_{2}$. There are a lot of works addressed to development new methods for $\mathrm{H}_{2} \mathrm{O}_{2}$ production, for example direct $[69,70]$.

Upon completion of the reaction, the quantity of iron leached to the reaction solution was determined to equal 0.26 to $2.24 \%$. Experimental studies of the catalytic contribution of homogeneous $\mathrm{Fe}^{3+}$ ion leached from the catalyst surface during methane oxidation were carried out using the filtered-out solution taken after the methane oxidation over the Commercial activated catalyst (Table 2 , entry 8$)$ and a homogeneous catalyst $(0.31 \mathrm{mM}$ iron nitrate) with the concentration of iron cation identical to that in the Commercial catalyst. In the former experiment, the iron cations leached from the solid catalyst were catalytically active neither to decomposition of hydrogen peroxide nor to oxidation of methane and its oxygenates. In the latter experiment, the homogeneous catalyst was very low active to methane oxidation and almost 100 $\%$ selective for $\mathrm{CO}_{2}$. At the same time, this catalyst was highly active to decomposition of hydrogen peroxide: the observed TOF $\left(683 \mathrm{~h}^{-1}\right)$ was higher of those of all the silicalites under study but lower of that of the Commercial catalyst. Hence, the leached $\mathrm{Fe}^{3+}$ ion may only contribute to decomposition of hydrogen peroxide but scarcely to deep oxidation of methane.

Main products of the methane oxidation in our experiments were methanol, formic acid and $\mathrm{CO}_{2}$. The quantity of carbon monoxide was by an order of magnitude less in comparison with the quantities of the other products (the selectivity is ca. $1 \%$ ) (Table 2). It was discussed above that the quantity of methylhydroperoxide is much less than a total of three main products, while at the present stage we failed to determine accurately the concentration of formaldehyde hydrate. That was why we estimated TOF of the methane oxidation based on the yields of methanol, formic acid and $\mathrm{CO}_{2}$ (Table 2). TOF varies from 20 to $340 \mathrm{~h}^{-1}$ and increases in the series of both activated and not activated samples: Nanocrystals $<$ Microcrystals $<$ Commercial. With all the catalysts, TOF is observed to increase after the activation, the increase being more than twice with the Commercial catalyst (from 140 to $340 \mathrm{~h}^{-1}$ ).

The catalyst selectivities to the main products and the changes resulting from the catalyst activation were studied. The Commercial catalyst (Table 2, entry 5) was most active to the methane conversion and selective to the first oxygenated product (methanol, $36 \%$ ), while the Nanocrystals (Table 2, entry 1) least active but selective to the product of complete oxidation $\left(\mathrm{CO}_{2}, 44 \%\right)$. The Microcrystals (Table 2, entry 3 ) was highly selective to formic acid (64\%). A total of the selectivity to $\mathrm{HCOOH}$ and $\mathrm{CO}_{2}$ was ca. $80-85 \%$, the higher a selectivity to $\mathrm{HCOOH}$ the lower selectivity to $\mathrm{CO}_{2}$. These observations may indicate different pathways of the methane oxidation on the catalysts under study. It seems also that formic acid is not an intermediate of methanol oxidation to $\mathrm{CO}_{2}$. 
The activation with oxalic acid results in the formation of extralattice $\mathrm{FeO}_{\mathrm{x}}$-sites (Fig. 4) and in an increase in the total acidity of the catalysts; a decrease in the selectivity to $\mathrm{CO}_{2}$ and methanol at a considerable increase in the selectivity to formic acid is observed with all the samples under study. The selectivity to formic acid is as high as $84 \%$ over the Commercial activated catalyst (Table 2, entry 6). Thus, the formation of extralattice $\mathrm{FeO}_{\mathrm{x}}$-sites and an increase in the total acidity are the key factors in the process of the methane peroxide oxidation.

The selectivity to $\mathrm{HCOOH}$ correlates to the number of strong Brönsted acid sites and to the concentration/size of $\mathrm{Fe}$ oxide clusters (olygomeric complex or $\mathrm{Fe}_{2} \mathrm{O}_{3}$-like nanoparticle) but inversely proportional to the strength of the Brönsted acid sites. The Brönsted acid sites promote the activation of methane. These are bridge $\mathrm{Si}(\mathrm{OH}) \mathrm{Fe}$ and $\mathrm{Si}(\mathrm{OH}) \mathrm{Al}$ in the Fe-silicalite and $\mathrm{H}-$ ZSM-5, respectively, where Fe(III) ions are in tetrahedral environment (UV-Vis DR, bands at 22000 and $26000 \mathrm{~cm}^{-1}$, Fig. 3). The higher concentration of the Brönsted acid sites, the more selective transformation of $\mathrm{CH}_{4}$ to $\mathrm{HCOOH}$ [15]. However, this relationship varies as the strength of the Brönsted acid sites increases, that brings about differences in the selectivity to HCOOH observed with the Fe-silicalites and Commercials H-ZSM-5.

The fact that the selectivity decreases significantly with respect to $\mathrm{CO}_{2}$ but increases to $\mathrm{HCOOH}$ upon the catalyst activation may be accounted for by three reasons. First, this is a strong interaction of $\mathrm{HCOOH}$ with $\mathrm{Fe}^{3+}$ ions. The iron complexation by the reaction intermediate may prevent further oxidation of $\mathrm{HCOOH}[71,72]$. Seemingly, as the stability of Fe(III)-formate complexes depends on the nature of the $\mathrm{Fe}^{3+}$ complex, binuclear and oligomeric oxo-clusters are more stable than the isolated ions and $\mathrm{Fe}_{2} \mathrm{O}_{3}$-like nanoparticles [72]. Second, this is a stabilization of a high-valent oxoiron complex (ferryl species $\mathrm{Fe}^{\mathrm{IV}}=\mathrm{O}$ ) formed by a interaction of surface $\mathrm{Fe}^{2+}$ ions with hydrogen peroxide molecules in the Fe-oxide clusters. Ferryl species are known to be less active, but much more selective oxidant than $\mathrm{OH} \bullet$ radical [73]. Third, the nuclearity and the mechanism of the activated complex generation may play an important role. For example, the hemolytic mechanism of cleavage of the peroxide $\mathrm{O}-\mathrm{O}$ bond is characteristic of mononuclear complexes of iron [74]. Therefore, mononuclear complexes can initiate theformation of free radicals which are responsible for non-selective free-radical oxidation of methane to $\mathrm{CO}_{2}$, the mononuclear center $\mathrm{Fe}^{\mathrm{IV}}=\mathrm{O}$ being a milder oxidant than binuclear centers formed by the heterolytic mechanism [75]. It is reasonable to suppose that the non-activated catalysts containing predominantly mononuclear centers (isolated $\mathrm{Fe}^{3+}$ ions) provide the formation of methanol to be reoxidized to $\mathrm{CO}_{2}$ by the radical mechanism. Upon activation with oxalic acid, the catalysts comprise $\alpha-\mathrm{Fe}_{2} \mathrm{O}_{3}$-like clusters which interact with $\mathrm{H}_{2} \mathrm{O}_{2}$ by the heterolytic mechanism to form surface strong $\mathrm{LFe}^{\mathrm{V}}=\mathrm{O}$ and $/$ or $\mathrm{L}^{\cdot+} \mathrm{Fe}^{\mathrm{IV}}=\mathrm{O}$ ( $\mathrm{L}$ is a ligand) centers to catalyze methane oxidation to $\mathrm{HCOOH}$ (probably, through formaldehyde). Besides, the 
1 formation of the ferryl species in the aqueous solution of $\mathrm{H}_{2} \mathrm{O}_{2}$ is more probable for activated 2 catalysts containing more Fe-oxide clusters [47]. Again, the rise in the catalyst acidity can favor 3 changes in the mechanism (towards heterolytic) of the cleavage of $\mathrm{O}-\mathrm{O}$ bond to produce an active high-valent iron complex which is more selective to formic acid [29]. Therefore, the effect of increasing the selectivity to $\mathrm{HCOOH}$ is most pronounced with the Commercial activated sample where acid Fe-oxide-containing sites are stronger and more numerous in number than those in the Fe-silicalites. The linear correlation is observed between the $\mathrm{NH}_{3}$ uptake and $\mathrm{HCOOH}$ selectivity over the activated samples (Fig. 10). There is no correlation between the $\mathrm{NH}_{3}$ uptake and $\mathrm{HCOOH}$ conversion over the calcined samples before their activation due to a lower number of catalytically active Fe oxide sites and their low exposure to $\mathrm{HCOOH}$. However, we should note that this correlation is based on three data points only. Additional study is required to make this observation more solid.

Regarding selectivity to methanol, it can be considered as a product of direct oxidation of methane, which is thought to form through interaction of methyl and hydroxyl free radicals in the presence of zeolite catalysts [76]. While the radical mechanism is characteristic of the formation of methanol, one can assume that the selectivity to $\mathrm{CH}_{3} \mathrm{OH}$ depends on three factors, which are the external surface area (determines the rate of radical quenching), concentrations of strong acid sites and $\mathrm{Fe}^{3+}$ ions (active to the formation of methyl and hydroxyl radicals, respectively) [71]. The influence of external surface area (and, hence, of the crystallite size) is most pronounced. The selectivity to $\mathrm{CH}_{3} \mathrm{OH}$ is lowest over the Nanocrystal sample (Table 2, entry 1) with the largest external surface area and highest over the initial Commercial sample with the lowest surface area, which consists of the large accreted aggregates (Table 2, entry 5).

The data on methane peroxide oxidation over Fe-containing zeolites calculated based on literature data $[46,77]$ are also given in Table 2 (entry 10-14). Note that the zeolite modulus as well as Fe loadings of the catalysts $[46,77]$ differ from our catalysts.. The comparison showed that our Commercial catalyst (both activated and initial) has a much higher TOF in methane oxidation than most of the catalysts studied by other groups. An exception is 0.014Fe-ZSM-5-15 explored by Hammond et al. in [46], the highest TOF $\left(2393 \mathrm{~h}^{-1}\right)$ of this catalysts is accounted for by the extremely low content of iron. Simultaneously, the activated Commercial catalyst showed the best $\mathrm{H}_{2} \mathrm{O}_{2}$ efficiency (TOF $\left(\mathrm{H}_{2} \mathrm{O}_{2}\right) / \mathrm{TOF}\left(\mathrm{CH}_{4}\right)$ ratio) and a highest selectivity to formic acid.

\subsection{Peroxide oxidation of methanol and formic acid}

The hypothesis on different routes to methane oxidation products was checked through experimental studies of oxidation of methanol and formic acid in argon atmosphere in the presence of Commercial and Commercial activated catalysts, which were most active to methane 
1 oxidation; the oxidation of methane in the presence of the reaction products (methanol and 2 formic acid) also was studied (Table 3). The following was observed.

First, there is observed a considerable influence of the substrate on the conversion of hydrogen peroxide. In the substrate oxidation in argon, TOF $\left(\mathrm{H}_{2} \mathrm{O}_{2}\right)$ increases in the series methane $<$ formic acid $<$ methanol, TOF being varied from $950 \mathrm{~h}^{-1}$ to $2550 \mathrm{~h}^{-1}$ (Commercial catalyst (Table 3 , entry $1,2,4)$ ) and from $1400 \mathrm{~h}^{-1}$ to $3190 \mathrm{~h}^{-1}$ (Commercial activated catalyst (Table 3 , entry $6,7,8)$ ). In the reaction of methanol oxidation (Table 3, entry 2, 7) TOF $\left(\mathrm{H}_{2} \mathrm{O}_{2}\right)$ is close to TOF observed during decomposition of pure hydrogen peroxide: $2630 \mathrm{~h}^{-1}$ over the Commercial and $3480 \mathrm{~h}^{-1}$ over the Commercial activated catalysts. In oxidation of methane in the presence of $\mathrm{CH}_{3} \mathrm{OH}$ and $\mathrm{HCOOH}$ (Table 3, entry 3, 5, 8, 10), TOF $\left(\mathrm{H}_{2} \mathrm{O}_{2}\right)$ is by a factor of 1.5-3 below but remains higher than that in oxidation pure methane. Note that the solubility of methane in water is $164 \mathrm{mM}$ at $323 \mathrm{~K}$ and 30 bar [78], this is more than 3 times of the initial concentrations of methanol and formic acid $(50 \mathrm{mM})$ in our experiments. The observed phenomena lead to suppose that the same Fe-containing sites take part both in decomposition of $\mathrm{H}_{2} \mathrm{O}_{2}$ and in adsorption of $\mathrm{CH}_{4}$, the methane adsorption being strong enough to prevent the sites from their participation in the decomposition of hydrogen peroxide. Similar to In- and Znmodified ZSM-5 [79, 80], nonframework Fe oxide clusters may behave as the adsorption sites. The second reason for decreasing TOF $\left(\mathrm{H}_{2} \mathrm{O}_{2}\right)$ may be the change in the free radical (Fentonlike) the route of $\mathrm{H}_{2} \mathrm{O}_{2}$ decomposition to the heterogeneous route. The free radical mechanism implies the formation of $\mathrm{OH} \bullet$ and $\mathrm{HOO} \bullet$ radicals as initiated by the $\mathrm{Fe}^{3+} / \mathrm{Fe}^{2+}$ transition [68], while the latter involves generation of ferryl ions $\left(\mathrm{FeO}^{2+}\right)[29]$. The increasing TOF $\left(\mathrm{H}_{2} \mathrm{O}_{2}\right)$ for methane oxidation in the presence of methanol or formic acid may be accounted for by additional routes to spend $\mathrm{H}_{2} \mathrm{O}_{2}$ - via auto-catalyzed reaction of formic acid oxidation to performic acid [81] and homogeneous oxidation of methanol [68, 82].

Second, $100 \%$ conversion of methanol was observed with the both catalysts in the argon atmosphere, while the overall yield of the detected products $\left(\mathrm{HCOOH}, \mathrm{CO}\right.$ and $\left.\mathrm{CO}_{2}\right)$ was $53 \%$ with the Commercial (Table 3, entry 2) and $59 \%$ with the Commercial activated (Table 3, entry 7) catalysts. The misbalance can result from: 1) a high yield of formaldehyde (not detected in our experiments), and 2) the oxidation of methanol into gaseous products following the catalyst removal during the storage and preparation the reaction solution to the analysis. While methanol was oxidized at a much higher rate during storage of the sample than during the reaction of methane oxidation, the measured methanol concentration may be underestimated. However, the catalytic activity of homogeneous $\mathrm{Fe}^{3+} / \mathrm{Fe}^{2+}$ ions was not observed in the experiments on decomposition of hydrogen peroxide or oxidation of methanol in the presence of the filtrate 
1 radical mechanism of the methanol oxidation and for the absence of contribution of 2 homogeneous $\mathrm{Fe}^{3+} / \mathrm{Fe}^{2+}$ ions to the oxidation of methanol.

Third, the conversion of methanol and yield of $\mathrm{CO}_{2}$ decreased considerably (by a factor of 2-9) during oxidation of methane over both catalysts in the presence of $\mathrm{CH}_{3} \mathrm{OH}$ and $\mathrm{HCOOH}$ (Table 3, entry $3,5,8,10$ ) against the data obtained by oxidation of $\mathrm{CH}_{3} \mathrm{OH}$ and $\mathrm{HCOOH}$ in argon (Table 3, entry 2, 4, 7, 9). The conversions of methanol and formic acid were estimated by comparing the quantities of oxygenates detected among the reaction products. In the reaction of methanol oxidation, the quantity decreased from $4.00 \mathrm{mmol}$ (initial) to 1.54 and $2.13 \mathrm{mmol}$ over the Commercial and Commercial activated catalysts, respectively.

These were as high as 2.5 and 5 times of the methanol quantities obtained from methane over the Commercial and Commercial activated catalysts, respectively. With the Commercial catalyst, the yield of formic acid in the presence of methane was almost 5 times as high as that in the presence of argon; these were the yields comparable to the results obtained with the Commercial activated catalysts.

Forth, formic acid is not consumed during oxidation in the presence of methane but accumulated; the $\mathrm{HCOOH}$ quantity increases from $4.00 \mathrm{mmol}$ to 6.70 and $5.11 \mathrm{mmol}$ over the Commercial (Table 3, entry 5) and Commercial activated (Table 3, entry 10). Some lower quantity of formic acid detected with the Commercial activated than with Commercial is thought to result from a higher activity of the former to oxidation of formic acid to $\mathrm{CO}_{2}$ (see the results on $\mathrm{HCOOH}$ oxidation in argon). Note that the yield of $\mathrm{HCOOH}$ over Commercial is high during methanol oxidation in the presence of methane than during oxidation of methane and methanol in argon. However, methanol quantities are comparable during formic acid oxidation in the presence of methane and during methane oxidation, the influence of the catalyst composition being negligible.

Fifth, similar to the case of the peroxide oxidation of methane, the selectivity to $\mathrm{HCOOH}$ (expressed as the full methanol conversion) was higher with the Commercial activated (46.3\%) (Table 3, entry 7) than with the Commercial (35.5\%) catalysts (Table 3, entry 2). As to the selectivity to $\mathrm{CO}_{2}$, the Commercial catalyst was more selective but the Commercial activated was more active to the peroxide oxidation of $\mathrm{HCOOH}$ to $\mathrm{CO}_{2}$ (conversion $79 \%$ ) than the Commercial catalyst (conversion $68 \%$ ). Thus, the catalyst activation through the treatment with oxalic acid affects similarly the catalyst selectivity in the reactions of methane and methanol oxidation. The oxidation of methanol produced by methane oxidation and of methanol added to the reaction solution seems to follow the same routes. At the same time, oxidation of formic acid produced by methane oxidation and the acid added to the solution follow different routes. It seems like formic acid added to the solution promotes polarization of the peroxide $\mathrm{O}-\mathrm{O}$ bond 
1 (probably due to a decrease in $\mathrm{pH}$ of the solution (Table 3)); as a result, oxidation of methane to

$2 \mathrm{HCOOH}$ over Commercial and to $\mathrm{CO}_{2}$ over Commercial activated is accelerated due to a 3 combination of both heterogeneous and homogeneous routes involving performic acid. The difference in the selectivity to methane oxidation over Commercial and Commercial activated catalysts in the presence of formic acid may be accounted for by the different contributions of heterogeneous/homogeneous routes, as well as by the different activities of isolated $\mathrm{Fe}^{3+}$ ions and binuclear/oligomeric oxo-clusters of Fe-ions.

The reported regularities of the peroxide oxidation of methane, methanol and formic acid support the formulated hypothesis (see Section 3.4) on different mechanisms of oxidation of the said substrates. Evidently, the heterogeneous route is characteristic of the transformations of methane and formic acid, when the active sites are formed via interaction of binuclear/oligomeric oxo-clusters of Fe-ions with $\mathrm{H}_{2} \mathrm{O}_{2}$. The free radical mechanism seems more probable for oxidation of methanol.

\section{Conclusions}

Formic acid is a widely used, readily biodegradable and low corrosive commodity chemical considered now as one of promising hydrogen storage materials due to its easily controlled dehydrogenation to $\mathrm{H}_{2}$ and $\mathrm{CO}_{2}$. Formic acid can be produced from methane which is one of most abundant and renewable carbon resource on our planet.

We studied in detail the influence of Fe-ZSM-5 zeolites properties such as the zeolite morphology (the crystallite size and texture properties) and structure of Fe-containing species inside the zeolite channels on the catalysts selectivity to partial peroxide oxidation of methane to formic acid. The catalysts of different morphology (nanosize, microsize, and bulky) were prepared, activated with an oxalic acid solution and characterized by UV-vis DR, ESR, $\mathrm{NH}_{3}$ $\mathrm{TPD},{ }^{27} \mathrm{Al}$ NMR. The activation caused transformation of isolated iron cations from tetrahedral framework oxygen surrounding to octahedral extraframework oxygen surrounding with simultaneous formation of oligomeric $\mathrm{Fe}$ oxo-clusters that led to an increase in the selectivity to formic acid and to a decrease in the selectivity to $\mathrm{CO}_{2}$ and methanol. We also tried to revise in detail the effect of addition of the reaction intermediates (methanol and formic acid) on the conversion and selectivity of the peroxide oxidation of methane. Peroxide oxidation of methanol and formic acid also were studied over initial and activated bulky catalysts.

The obtained data and regularities of the peroxide oxidation of methane, methanol and formic acid support the formulated hypothesis on different mechanisms of oxidation of methane over Fe-MFI catalysts. Evidently, the heterogeneous route is characteristic of the transformations of methane to formic acid, when the active sites are formed via interaction of oligomeric oxo- 
1 clusters of $\mathrm{Fe}$-ions with $\mathrm{H}_{2} \mathrm{O}_{2}$. The free radical mechanism seems more probable for oxidation of

2 methane to methanol and methanol to $\mathrm{CO}_{2}$.

3

Acknowledgments

The financial support of the Russian Science Foundation (grant 17-73-30032) is 5 gratefully acknowledged.

6 


\section{References}

1. Bulushev DA, Ross JRH (2018) ChemSusChem 11(5):821-836

2. Wang WH, Himeda Y, Muckerman JT, Manbeck GF, Fujita E (2015) Chem Rev 115(23):12936-12973

3. Eppinger J, Huang KW (2017) ACS Energy Letters 2(1):188-195

4. Onishi N, Laurenczy G, Beller M, Himeda Y (2018) Coord Chem Rev 373:317332

5. Schierz ER (1923) ACS 45(2):455-468

6. Supronowicz W, Ignatyev IA, Lolli G, Wolf A, Zhao L, Mleczko L (2015) Green Chem 17(5):2904-2911

7. Lee HJ, Kang DC, Pyen SH, Shin M, Suh YW, Han H, Shin CH (2017) Appl Catal A: Gen 531:13-20

8. Thauer RK (2010) Angew Chem Int Ed 49(38):6712-6713

9. Blanksby SJ, Ellison GB (2003) Acc Chem Res 36(4):255-263

10. Shilov AE, Shteinman AA (2012) Rus Chem Rev 81(4):291-316

11. Holmen A (2009) Catal Today 142(1-2):2-8

12. Hammond C, Forde MM, Ab Rahim MH, Thetford A, He Q, Jenkins RL, Dimitratos N, Lopez-Sanchez JA, Dummer NF, Murphy DM, Carley AF, Taylor SH, Willock DJ, Stangland EE, Kang J, Hagen H, Kiely CJ, Hutchings GJ (2012) Angew Chem Int Ed 51(21):5129-5133

13. Wei X, Ye L, Yuan Y (2009) J Nat Gas Chem 18(3):295-299

14. Boltenkov VV, Taran OP, Parkhomchuk EV, Yashnik SA, Sashkina KA, Ayusheev AB, Babushkin DE, Parmon VN (2016) J Sib Fed Un Chem 4(9):394-413

15. Rahman AKML, Kumashiro M, Ishihara T (2011) Catal Commun 12(13):11981200

16. Knops-Gerrits PP, Smith WJ (2000) Stud Surf Sci Catal 130:3531-3536

17. Otsuka K, Wang Y (2001) Appl Catal A: Gen 222(1-2):145-161

18. Kucherov AV, Nissenbaum VD, Kucherova TN, Kustov LM (2002) Kinet Catal 43(5):711-723

19. Benlounes O, Mansouri S, Rabia C, Hocine S (2008) J Nat Gas Chem 17(3):309312

20. Alvarez-Galvan MC, Mota N, Ojeda M, Rojas S, Navarro RM, Fierro JLG (2011) Catal Today 171(1):15-23 
21. Starokon EV, Parfenov MV, Arzumanov SS, Pirutko LV, Stepanov AG, Panov GI (2013) J Catal 300:47-54

22. Zhang Z, Guo Z, Ji S (2015) J Energ Chem 24(1):23-30

23. Zhu F, Zhu-Ge L, Yang G, Zhou S (2015) ChemSusChem 8(4):609-612

24. Burgess SA, Kendall AJ, Tyler DR, Linehan JC, Appel AM (2017) ACS Catal 7(4):3089-3096

25. Zolotarskii IA, Andrushkevich TV, Popova G, Stompel S, Efimov VO, Nakrokhin VB, Zudilina L, Vernikovskaya NV (2014) Chem Eng J 238:111-119

26. Danilevich EV, Popova GY, Andrushkevich TV, Kaichev VV, Danilova IG, Chesalov YA, Rogov VA, Bukhtiyarov VI, Parmon VN Appl Catal A: Gen 475:98-108

27. Romakh VB, Therrien B, Süss-Fink G, Shul'pin GB (2007) Inorg Chem 46(8):3166-3175

28. Yuan Q, Deng W, Zhang Q, Wang Y (2007) Adv Synth Catal 349(7):1199-1209

29. Sorokin AB, Kudrik EV, Alvarez LX, Afanasiev P, Millet JMM, Bouchu D (2010) Catal Today 157(1-4):149-154

30. Ab Rahim MH, Forde MM, Hammond C, Jenkins RL, Dimitratos N, LopezSanchez JA, Carley AF, Taylor SH, Willock DJ, Hutchings GJ (2013) Top Catal 56(1820):1843-1857

31. Olivos-Suarez AI, Szecsenyi A, Hensen EJM, Ruiz-Martinez J, Pidko EA, Gascon J (2016) ACS Catal 6(5):2965-2981

32. Shilov AE, Shul'pin GB (1997) Chem Rev 97(8):2879-2932

33. Copéret C (2010) Chem Rev 110(2):656-680

34. Centi G, Perathoner S, Torre T, Verduna MG (2010) Catal Today 55(1-2):61-69

35. Pestunova OP, Elizarova GL, Ismagilov ZR, Kerzhentsev MA, Parmon VN (2002) Catal Today 75(1-4):219-225

36. Makhotkina OA, Kuznetsova EV, Preis SV (2006) Appl Catal B: Env 68(3-4):8591

37. Kondru AK, Kumar P, Chand S (2009) J Haz Mat 166(1):342-347

38. Prihod'ko R, Stolyarova I, Gündüz G, Taran O, Yashnik S, Parmon V, Goncharuk V (2011) Appl Catal B: Env 104(1-2):201-210

39. Taran OP, Yashnik SA, Ayusheev AB, Piskun AS, Prihod'ko RV, Ismagilov ZR, Goncharuk VV, Parmon VN (2013) Appl Catal B: Env 140-141:506-515

40. Taran OP, Zagoruiko AN, Ayusheev AB, Yashnik SA, Prihod'Ko RV, Ismagilov ZR, Goncharuk VV, Parmon VN (2015) Res Chem Inter 41(12):9521-9537 
41. Snyder BER, Vanelderen P, Bols ML, Hallaert SD, Böttger LH, Ungur L, Pierloot K, Schoonheydt RA, Sels BF, Solomon EI (2016) Nature 536(7616):317-321

42. Grundner S, Luo W, Sanchez-Sanchez M, Lercher JA (2016) Chem Commun $52(12): 2553-2556$

43. Kuzmin AO, Elizarova GL, Matvienko LG, Savinova ER, Parmon VN (1998) Mend Commun 8(6):210-212

44. Lysova AA, Kuzmin AO, Elizarova GL, Parmon VN (2002) Kinet Catal 43(6):778-784

45. Hammond C, Dimitratos N, Lopez-Sanchez JA, Jenkins RL, Whiting G, Kondrat SA, Ab Rahim MH, Forde MM, Thetford A, Hagen H. Stangland EE, Kang JH, Moulijn JM, Willock DJ, Hutchings GJ (2013) ACS Catal 3(8):1835-1844

46. Hammond C, Dimitratos N, Jenkins RL, Lopez-Sanchez JA, Kondrat SA, Ab Rahim MH, Forde MM, Thetford A, Taylor SH, Hagen H, Stangland EE, Moulijn JM, Taylor SH, Willock DJ, Hutchings GJ (2013) ACS Catal 3(4):689-699

47. Shubin AA, Ruzankin SP, Zilberberg IL, Parmon VN (2015) Chem Phys Lett 640:94-100

48. Parkhomchuk EV, Vanina MP, Preis S (2008) Catal Commun 9(3):381-385

49. Yashnik SA, Ismagilov ZR, Anufrienko VF (2005) Catal Today 110(3-4):310-322

50. Gregg SJ, Sing KSW (1982) Adsorption, surface area, and porosity. Academic Press, London

51. Barrett EP, Joyner LG, Halenda PP (1951) J Am Chem Soc 73(1):373-380

52. Jaroniec M, Kruk M, Olivier JP (1999) Langmuir 15(16):5410-5413

53. Kruk M, Jaroniec M, Ko CH, Ryoo R (2000) Chem Mat 12(7):1961-1968

54. Sashkina KA, Parkhomchuk EV, Rudina NA, Parmon VN (2014) Micropor Mesopor Mat 189:181-188

55. Sashkina KA, Gurikov PA, Ayupov AB, Smirnova I, Parkhomchuk EV (2018) Micropor Mesopor Mat 263:106-112

56. Lever ABP (1984) Inorganic Electron Spectroscopy. Elsevier, Amsterdam

57. Malykhin SE, Anufrienko VF, Hansen EJM, Kuznetsova EV, Larina TV, Zhidomirov GM (2007) J Struct Chem 48(5):855-861

58. Zhilinskaya EA, Delahay G, Mauvezin M, Coq B, Aboukaïs A (2003) Langmuir 19(9):3596-3602

59. Wichterlova B, Kubelkova L, Jiru P, Kolihova D (1980) Collect Czech Chem Commun 45:2143 
60. Jänchen J, Vorbeck G, Stach H, Parlitz B, van Hooff JHC (1995) Stud Surf Sci Catal 94:108-115

61. Lónyi F, Valyon J (2001) Micropor Mesopor Mat 47(2-3):293-301

62. Gorte RJ (1999) Catal Lett 62(1):1-13

63. Katada N, Igi H, Kim JH, Niwa M (1997) J Phys Chem B 101(31):5969-5977

64. Sashkina KA, Polukhin AV, Labko VS, Ayupov AB, Lysikov AI, Parkhomchuk EV (2016) Appl Catal B: Env 185:353-361

65. Koptyug IV, Kulikov AV, Lysova AA, Kirillov VA, Parmon VN, Sagdeev RZ (2003) Chem Sustain Develop 11:109-116

66. Blümich B, Datsevich LB, Jess A, Oehmichen T, Ren X, Stapf S (2007) Chem Eng J 134(1-3):35-44

67. Forde MM, Armstrong RD, Hammond C, He Q, Jenkins RL, Kondrat SA, Dimitratos N, Lopez-Sanchez JA, Taylor SH, Willock D, Kiely CJ, Hutchings GJ (2013) J Am Chem Soc 135(30):11087-11099

68. Sychev AY, Isak VG (1995) Rus Chem Rev 64(12):1105-1129

69. Mizuno N, Centi G, Perathoner S, Abate S (2009) Modern Heterogeneous Oxidation Catalysis: Design, Reactions and Characterization. Wiley-VCH 253-287

70. Edwards JK, Solsona BN, Edwin NN, Carley AF, Herzing AA, Kiely CJ, Hutchings GJ, (2009) Science 323(5917):1037-1041

71. Foustoukos DI, Stern JC (2012) Geochim Cosmochim Acta 76:14-28

72. Long Y, Charbouillot T, Brigante M, Mailhot G, Delort AM, Chaumerliac N, Deguillaume L (2013) Atmos Env 77:686-695

73. Gonzalez-Olmos R, Holzer F, Kopinke FD, Georgi A (2011) Appl Catal A: Gen $398(1-2): 44-53$

74. Nam W, Han HJ, Oh SY, Lee YJ, Choi MH, Han SY, Kim C, Woo SK, Shin W (2000) J Am Chem Soc 122(36):8677-8684

75. Afanasiev P, Sorokin AB (2016) Acc Chem Res 49(4):583-593

76. Han S, Martenak DJ, Palermo RE, Pearson JA, Walsh DE (1992) J Catal $136(2): 578-583$

77. Kalamaras C, Palomas D, Bos R, Horton A, Crimmin M, Hellgardt K (2016) Catal Lett 146:483-492

78. Namiot AY (1991) Rastvorimost' gazov v vode. Nedra, Moscow

79. Arzumanov SS, Moroz IB, Freude D, Haase J, Stepanov AG (2014) J Phys Chem C 118(26):14427-14432 
80. Gabrienko AA, Arzumanov SS, Luzgin MV, Stepanov AG, Parmon VN (2015) J Phys Chem C 119(44):24910-24918

81. Sun X, Zhao X, Du W, Liu D (2011) Chinese J Chem Engin 19: 964-971

82. Fry SH, Payne JH (1931) J Am Chem Soc 53:1973-1980 


\section{Tables}

Table 1. Physicochemical characteristics of Fe-containing catalysts and kinetics data for $\mathrm{H}_{2} \mathrm{O}_{2}$ decomposition $\left(323 \mathrm{~K}, 1 \mathrm{M} \mathrm{H} \mathrm{H}_{2} \mathrm{O}_{2}, 20 \mathrm{~g} \cdot \mathrm{L}^{-1}\right.$ catalyst) [14].

\begin{tabular}{|c|c|c|c|c|c|c|c|c|c|c|}
\hline \multirow[t]{2}{*}{ Entry } & \multirow{2}{*}{$\begin{array}{c}\text { Fe-silicalite/ } \\
\text { zeolite sample }\end{array}$} & \multirow{2}{*}{$\begin{array}{c}\text { Fe } \\
\text { content, } \\
\text { wt. \% }\end{array}$} & \multirow{2}{*}{$\begin{array}{l}\mathrm{S}_{\mathrm{BET}}, \\
\mathrm{m}^{2} \mathrm{~g}^{-1}\end{array}$} & \multirow{2}{*}{$\begin{array}{l}\mathrm{S}_{\mathrm{Ext}} \\
\mathrm{m}^{2} \mathrm{~g}^{-1}\end{array}$} & \multirow{2}{*}{$\begin{array}{l}\mathrm{V}_{\text {total }}, \\
\mathrm{cm}^{3} \mathrm{~g}^{-1}\end{array}$} & \multirow{2}{*}{$\begin{array}{l}\mathrm{V}_{\text {micro }} \\
\mathrm{cm}^{3} \mathrm{~g}^{-1}\end{array}$} & \multirow{2}{*}{$\begin{array}{c}\text { Total } \mathrm{NH}_{3} \text { adsorption } \\
\text { capacity, } \\
\mathrm{mmol} \mathrm{g}^{-1}\end{array}$} & \multicolumn{3}{|c|}{$\mathrm{H}_{2} \mathrm{O}_{2}$} \\
\hline & & & & & & & & $\begin{array}{c}\mathrm{k} \cdot 10^{3}, \mathrm{sec}^{-} \\
1\end{array}$ & $\begin{array}{c}\text { TOF, } \\
\mathrm{h}^{-1}\end{array}$ & $\begin{array}{c}\mathrm{E}_{\mathrm{a}}, \\
\mathrm{kJ} \cdot \mathrm{mol}^{-1}\end{array}$ \\
\hline 1 & Nanocrystals & 1.32 & 524 & 234 & 0.68 & 0.12 & 0.15 & 1.50 & 1240 & $70 \pm 2$ \\
\hline 2 & $\begin{array}{c}\text { Nanocrystals } \\
\text { activated }\end{array}$ & 1.20 & 480 & 205 & 0.69 & 0.11 & 0.11 & 1.45 & 1340 & $84 \pm 5$ \\
\hline 3 & Microcrystals & 1.42 & 398 & 107 & 0.19 & 0.12 & 0.11 & 0.17 & 130 & $53 \pm 1$ \\
\hline 4 & $\begin{array}{c}\text { Microcrystals } \\
\text { activated }\end{array}$ & 1.42 & 437 & 117 & 0.22 & 0.13 & 0.17 & 2.44 & 1910 & $68 \pm 2$ \\
\hline 5 & Commercial & 0.65 & 517 & 19 & 0.28 & 0.13 & 0.23 & 1.54 & 2630 & $61 \pm 1$ \\
\hline 6 & $\begin{array}{c}\text { Commercial } \\
\text { activated }\end{array}$ & 0.65 & 426 & 12 & 0.23 & 0.17 & 0.27 & 2.04 & 3480 & $63 \pm 1$ \\
\hline
\end{tabular}


Table 2. Comparison of methane peroxide oxidation over Fe-containing catalysts. Data for entries 1-9 (except of pH and Fe leaching) from [14] (323 K, 30 bar, $30 \mathrm{~min}, 1 \mathrm{M} \mathrm{H}_{2} \mathrm{O}_{2}, 2.7 \mathrm{~g} \cdot \mathrm{L}^{-1}$ catalyst, $\left.\mathrm{pH}_{\text {initial }} 3.5\right)$ and literature data (entries 10-14).

\begin{tabular}{|c|c|c|c|c|c|c|c|c|c|c|c|c|c|}
\hline \multirow{2}{*}{ Entry } & \multirow{2}{*}{ Catalyst } & \multicolumn{2}{|c|}{$\mathrm{H}_{2} \mathrm{O}_{2}$} & \multicolumn{2}{|l|}{$\mathrm{CH}_{4}$} & \multirow{2}{*}{$\mathrm{TOF}\left(\mathrm{H}_{2} \mathrm{O}_{2}\right) / \mathrm{TOF}\left(\mathrm{CH}_{4}\right)$} & \multicolumn{4}{|c|}{ Selectivity, \% } & \multirow{2}{*}{$\mathrm{pH}_{\text {final }}$} & \multicolumn{2}{|c|}{ Fe leaching, } \\
\hline & & Conversion, $\%$ & TOF, $\mathrm{h}^{-1}$ & Conversion, $\%$ & TOF, $\mathrm{h}^{-1}$ & & $\mathrm{MeOH}$ & $\mathrm{HCOOH}$ & $\mathrm{CO}$ & $\mathrm{CO}_{2}$ & & $\mathrm{mg} \mathrm{L}^{-1}$ & $\%$ \\
\hline 1 & Nanocrystals & 12 & 360 & 0.14 & 20 & 16.2 & 14 & 41 & 1.6 & 44 & 3.1 & 0.1 & 0.28 \\
\hline 2 & Nanocrystals activated & 12 & 430 & 0.22 & 40 & 9.2 & 12 & 65 & 0.7 & 23 & 2.9 & 0.1 & 0.31 \\
\hline 3 & Microcrystals & 9 & 290 & 0.16 & 30 & 11.6 & 16 & 64 & 0.9 & 19 & 3.0 & 0.1 & 0.26 \\
\hline 4 & Microcrystals activated & 13 & 440 & 0.30 & 50 & 9.5 & 12 & 72 & 0.6 & 13 & 2.9 & 0.1 & 0.26 \\
\hline 5 & Commercial & 15 & 950 & 0.42 & 140 & 6.6 & 36 & 26 & 0.6 & 37 & 3.0 & 0.2 & 1.14 \\
\hline 6 & Commercial activated & 20 & 1400 & 1.02 & 340 & 4.2 & 10 & 84 & 0.9 & 5.1 & 2.8 & 0.4 & 2.28 \\
\hline 7 & Blank experiment & 0 & 0 & 0 & 0 & - & 0 & 0 & 0 & 0 & 3.5 & 0 & 0 \\
\hline 8 & Leaching test after Entry 6 & 0 & 0 & 0 & 0 & - & 0 & 0 & 0 & 0 & 2.7 & 0.4 & 0 \\
\hline 9 & $\mathrm{Fe}\left(\mathrm{NO}_{3}\right)_{3}$ & 10 & 680 & 0.02 & 6 & 68.3 & 0 & 0 & 1 & 99 & 1.9 & - & - \\
\hline 10 & $0.5 \mathrm{Fe}$-silicalite-1 [46] & 20 & 8230 & 0.29 & 75 & 109.7 & 20 & 61 & - & 7 & - & - & - \\
\hline $11 *$ & $0.014 \mathrm{Fe}-Z \mathrm{SM}-5-30-15$ [46] & 8 & 11850 & 0.26 & 2393 & 4.9 & 19 & 53 & & 5 & - & - & - \\
\hline $12 *$ & $0.5 \mathrm{Fe}-\mathrm{ZSM}-5-30-15$ [46] & 13 & 540 & 0.31 & 98 & 5.5 & 20 & 57 & & 14 & - & - & - \\
\hline $13 *$ & 2.5Fe-ZSM-5-30-15 [46] & 80 & 660 & 0.77 & 40 & 16.5 & 13 & 64 & - & 18 & - & - & - \\
\hline $14 *$ & 2.5Fe-ZSM-5-23-11 [77] & - & - & - & 21 & - & 13 & 64 & - & 24 & - & - & - \\
\hline
\end{tabular}

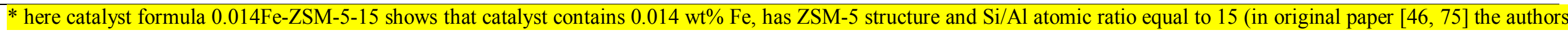
used molar ration $\mathrm{SiO}_{2} / \mathrm{Al}_{2} \mathrm{O}_{3}$ ). 
Table 3. Methanol and formic acid peroxide oxidation over Commercial and Commercial activated catalysts $\left(50 \mathrm{MM} \cdot \mathrm{L}^{-1} \mathrm{substrate}, 323 \mathrm{~K}, 30\right.$ bar, $30 \mathrm{~min}, 1 \mathrm{M} \mathrm{H}_{2} \mathrm{O}_{2}, 2.7 \mathrm{~g} \cdot \mathrm{L}^{-1}$ catalyst).

\begin{tabular}{|c|c|c|c|c|c|c|c|c|c|c|c|c|}
\hline \multirow[b]{2}{*}{ Entry } & \multirow[b]{2}{*}{ Catalyst } & \multirow[b]{2}{*}{ Substrate } & \multirow{2}{*}{$\begin{array}{l}\text { Gas } \\
\text { phase }\end{array}$} & \multicolumn{2}{|c|}{$\mathrm{H}_{2} \mathrm{O}_{2}$} & \multicolumn{2}{|c|}{ Substrate } & \multicolumn{4}{|c|}{ Products, mmol } & \multirow[b]{2}{*}{$\mathrm{pH}_{\text {fina }}$} \\
\hline & & & & $\begin{array}{c}\text { Conversion, } \\
\%\end{array}$ & $\begin{array}{l}\text { TOF, } \\
\mathrm{h}^{-1}\end{array}$ & $\begin{array}{c}\text { Conversion, } \\
\%\end{array}$ & $\begin{array}{c}\text { TOF, } \\
\mathrm{h}^{-1}\end{array}$ & $\mathrm{CH}_{3} \mathrm{OH}$ & $\mathrm{HCOOH}$ & $\mathrm{CO}$ & $\mathrm{CO}_{2}$ & \\
\hline 1 & Commercial & $\mathrm{CH}_{4}$ & $\mathrm{CH}_{4}$ & 15 & 950 & 0.42 & 140 & 0.63 & 0.45 & 0.01 & 0.66 & 3.0 \\
\hline 2 & Commercial & $\mathrm{CH}_{3} \mathrm{OH}$ & $\mathrm{Ar}$ & 40 & 2550 & 100 & - & 0 & 1.42 & 0.01 & 0.73 & 2.9 \\
\hline 3 & Commercial & $\mathrm{CH}_{3} \mathrm{OH}$ & $\mathrm{CH}_{4}$ & 31 & 1980 & - & - & 1.54 & 6.61 & 0.04 & 0.27 & 2.6 \\
\hline 4 & Commercial & $\mathrm{HCOOH}$ & $\mathrm{Ar}$ & 31 & 1980 & 68 & 220 & 0 & 1.19 & 0.01 & 2.72 & 2.9 \\
\hline 5 & Commercial & $\mathrm{HCOOH}$ & $\mathrm{CH}_{4}$ & 19 & 1210 & - & - & 0.54 & 6.70 & 0.04 & 0.33 & 2.6 \\
\hline 6 & Commercial activated & $\mathrm{CH}_{4}$ & $\mathrm{CH}_{4}$ & 22 & 1400 & 1.02 & 340 & 0.43 & 3.54 & 0.04 & 0.23 & 2.8 \\
\hline 7 & Commercial activated & $\mathrm{CH}_{3} \mathrm{OH}$ & $\mathrm{Ar}$ & 50 & 3190 & 100 & - & 0 & 1.85 & 0.01 & 0.50 & 2.9 \\
\hline 8 & Commercial activated & $\mathrm{CH}_{3} \mathrm{OH}$ & $\mathrm{CH}_{4}$ & 45 & 2870 & - & - & 2.13 & 2.09 & 0.04 & 0.21 & 2.8 \\
\hline 9 & Commercial activated & $\mathrm{HCOOH}$ & $\mathrm{Ar}$ & 45 & 2870 & 79 & 250 & 0 & 0.79 & 0.01 & 3.16 & 3.0 \\
\hline 10 & Commercial activated & $\mathrm{HCOOH}$ & $\mathrm{CH}_{4}$ & 23 & 1470 & - & - & 0.58 & 5.11 & 0.04 & 0.47 & 2.7 \\
\hline 11 & $\begin{array}{c}\text { Leaching test after } \\
\text { Entry } 5\end{array}$ & $\mathrm{CH}_{3} \mathrm{OH}$ & - & 0 & 0 & 0 & 0 & 4.00 & - & - & - & 3.5 \\
\hline
\end{tabular}


Figures

a

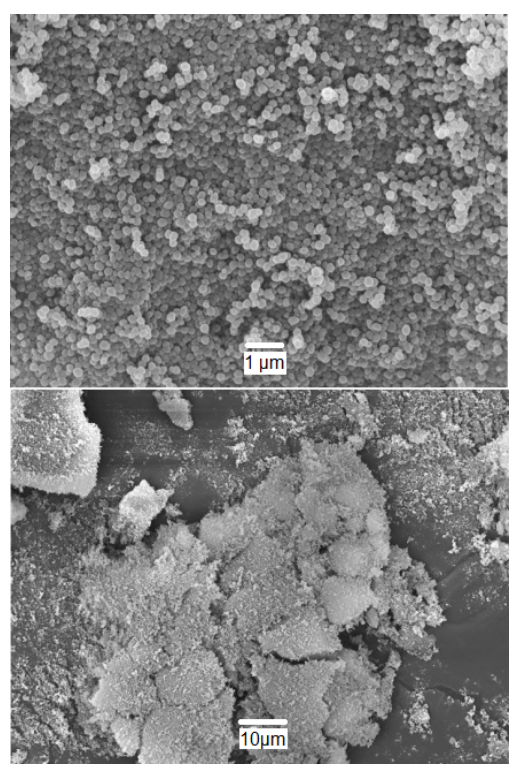

b

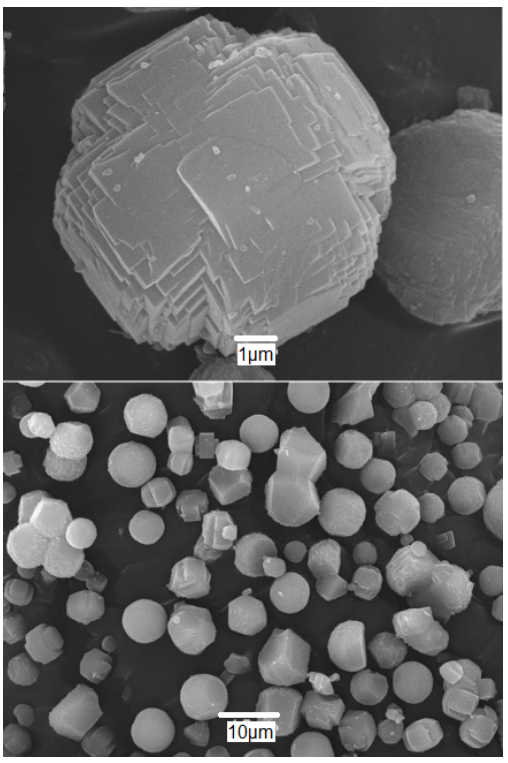

c

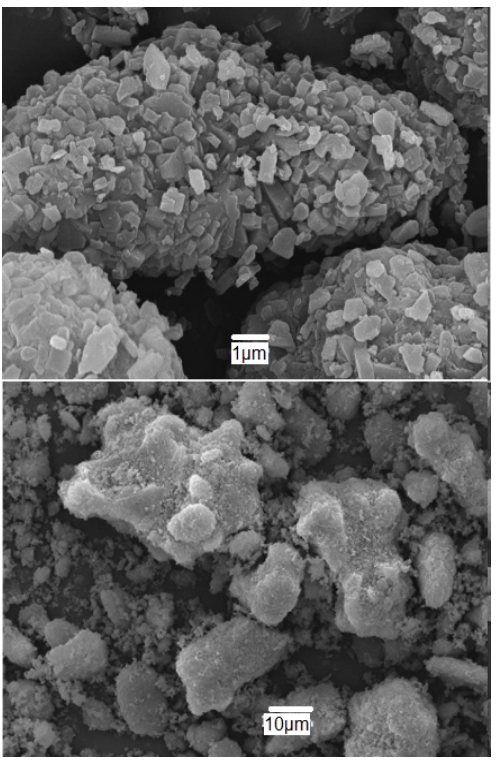

Figure 1.

SEM images of Fe-silicalite Nanocrystals (a), Fe-silicalite Microcrystals (b) [4] and Commercial Fe-ZSM-5 (c) at different magnifications.

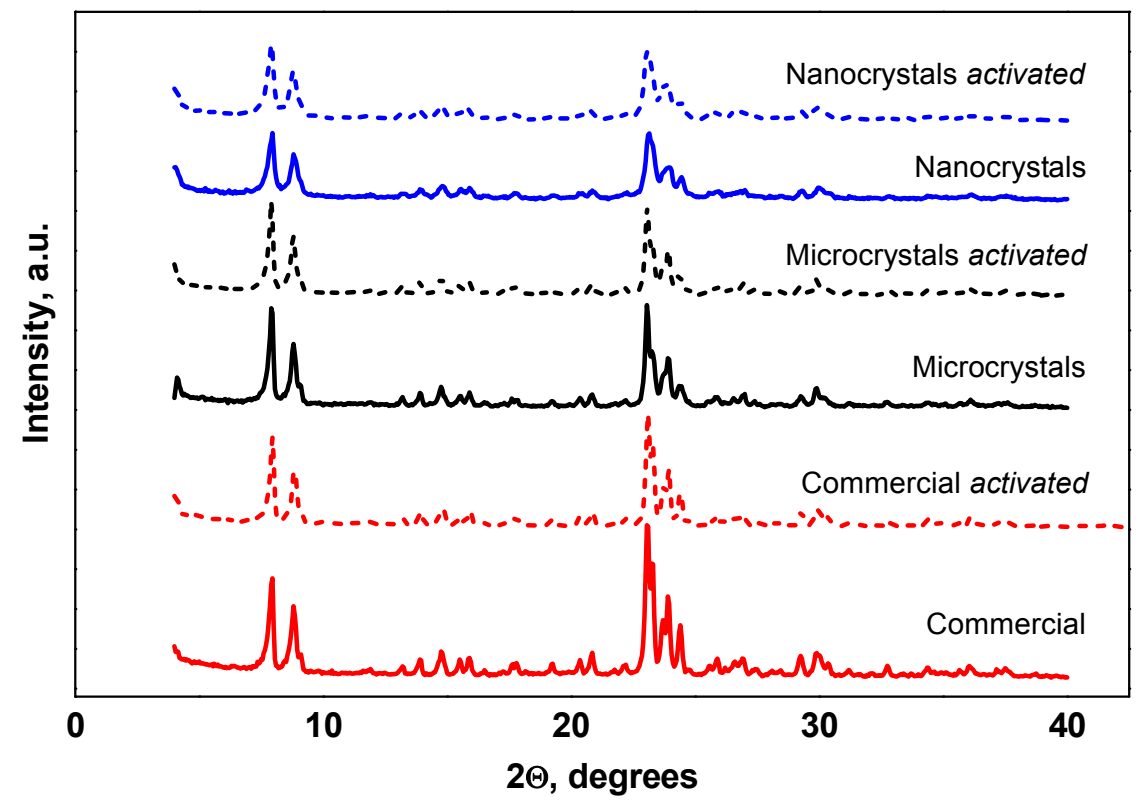

Figure 2.

XRD patterns of initial and activated Fe-silicalite samples synthesized and Commercial FeZSM-5. 


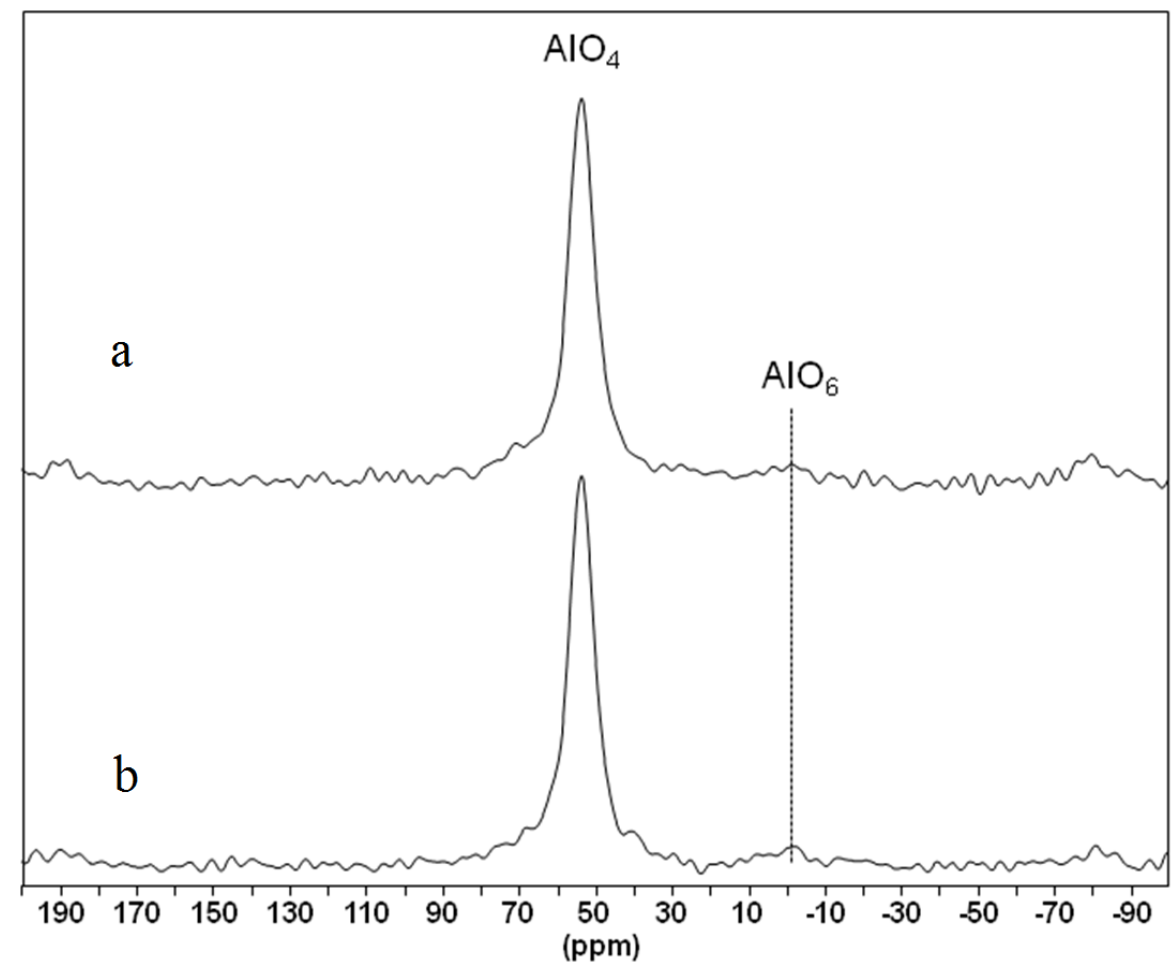

Figure 3.

${ }^{27}$ Al MAS NMR spectra for Commercial (a) and Commercial activated (b) Fe-ZSM-5.

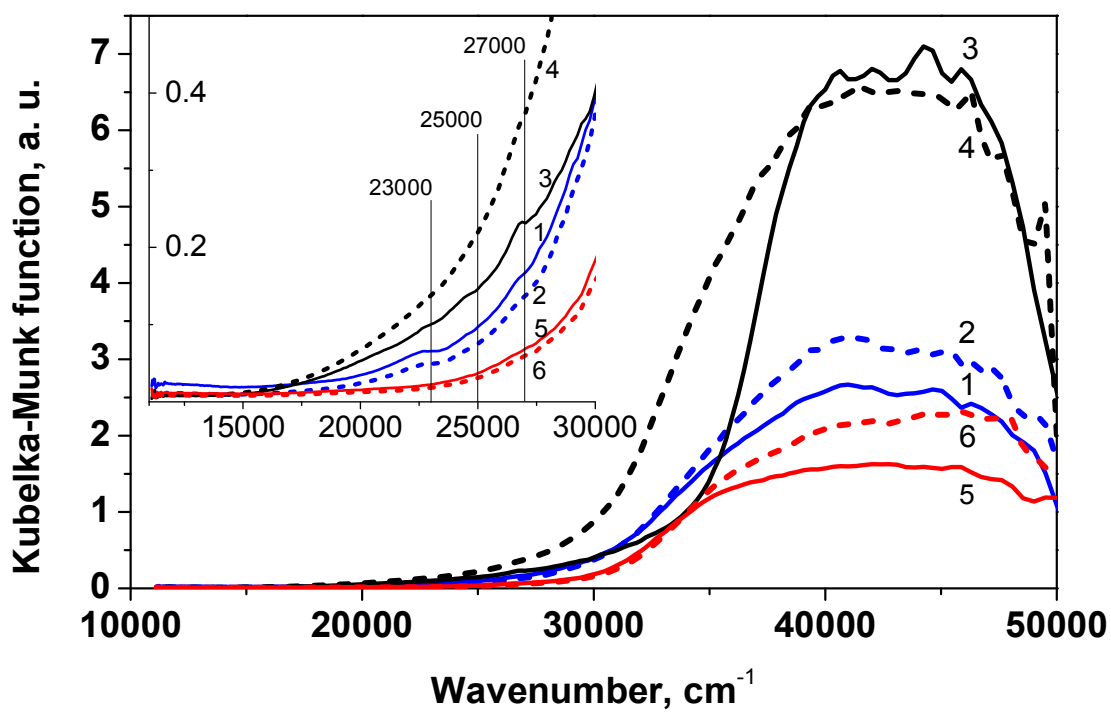

Figure 4.

UV-visible DR spectra of Fe-silicalite Nanocrystals (1) and Nanocrystals activated (2), Fesilicalite Microcrystals (3) and Microcrystals activated (4), Commercial (5) and Commercial activated (6) Fe-ZSM-5. 


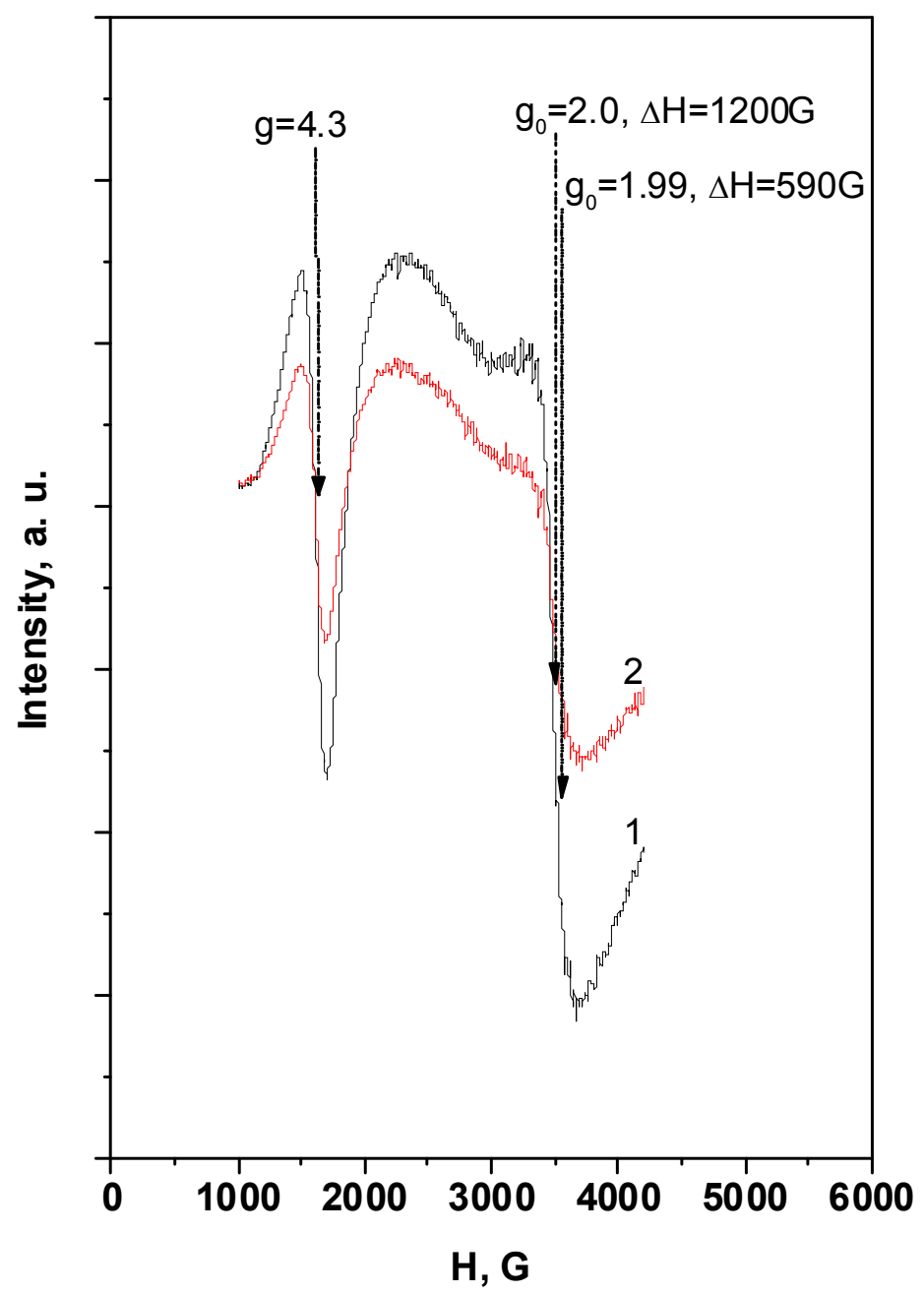

Figure 5a. ESR spectra of Fe-silicalites Nanocrystals (a), Microcrystals (b) and Commercial Fe-ZSM-5 (30) (c), before (1) and after activation in oxalic acid (2). Spectra were registered at $77 \mathrm{~K}$. 
b

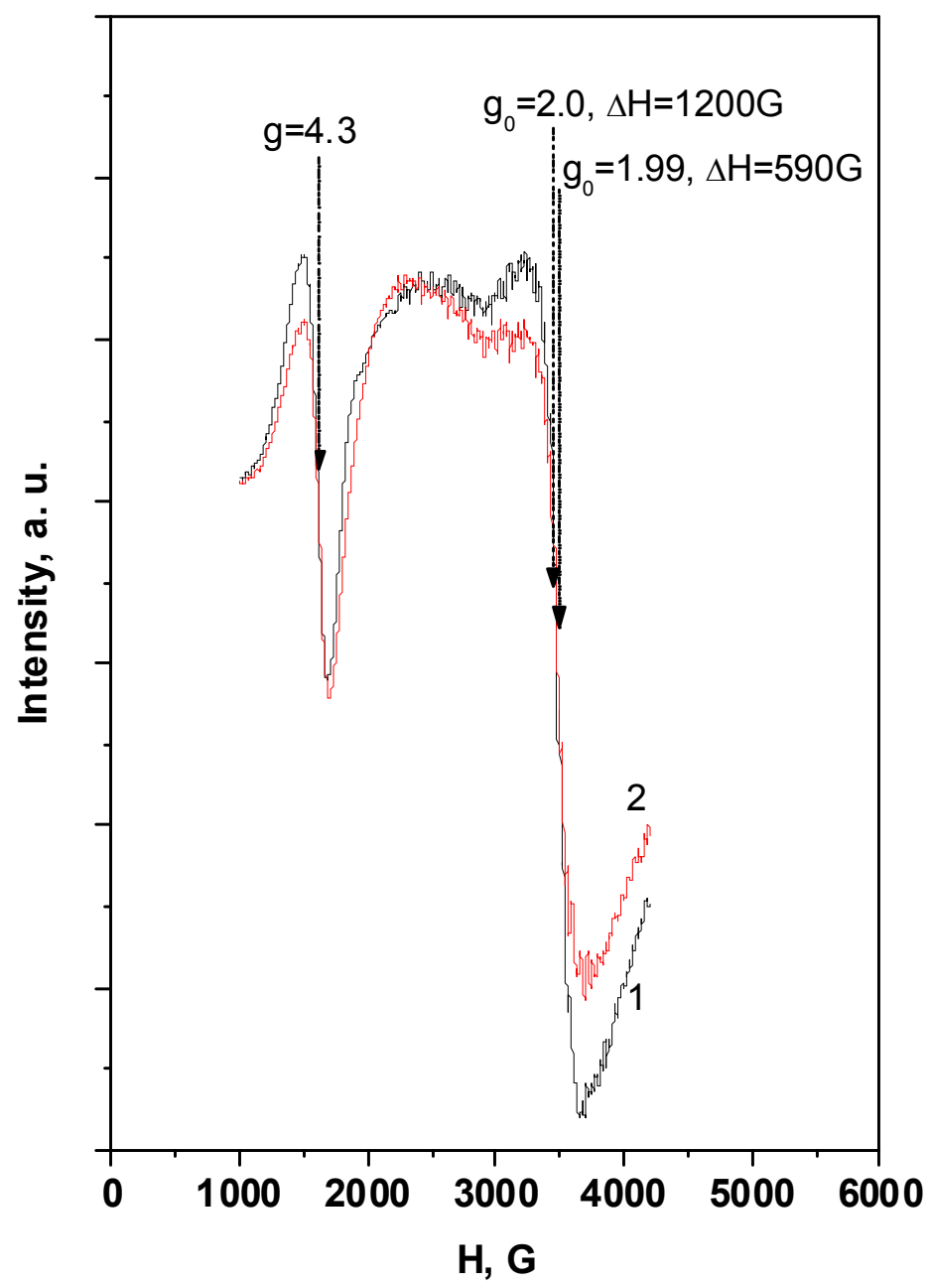

Figure 5b. ESR spectra of Fe-silicalites Nanocrystals (A), Microcrystals (B) and Commercial Fe-ZSM-5 (30) (C), before (1) and after activation in oxalic acid (2). Spectra were registered at $77 \mathrm{~K}$. 


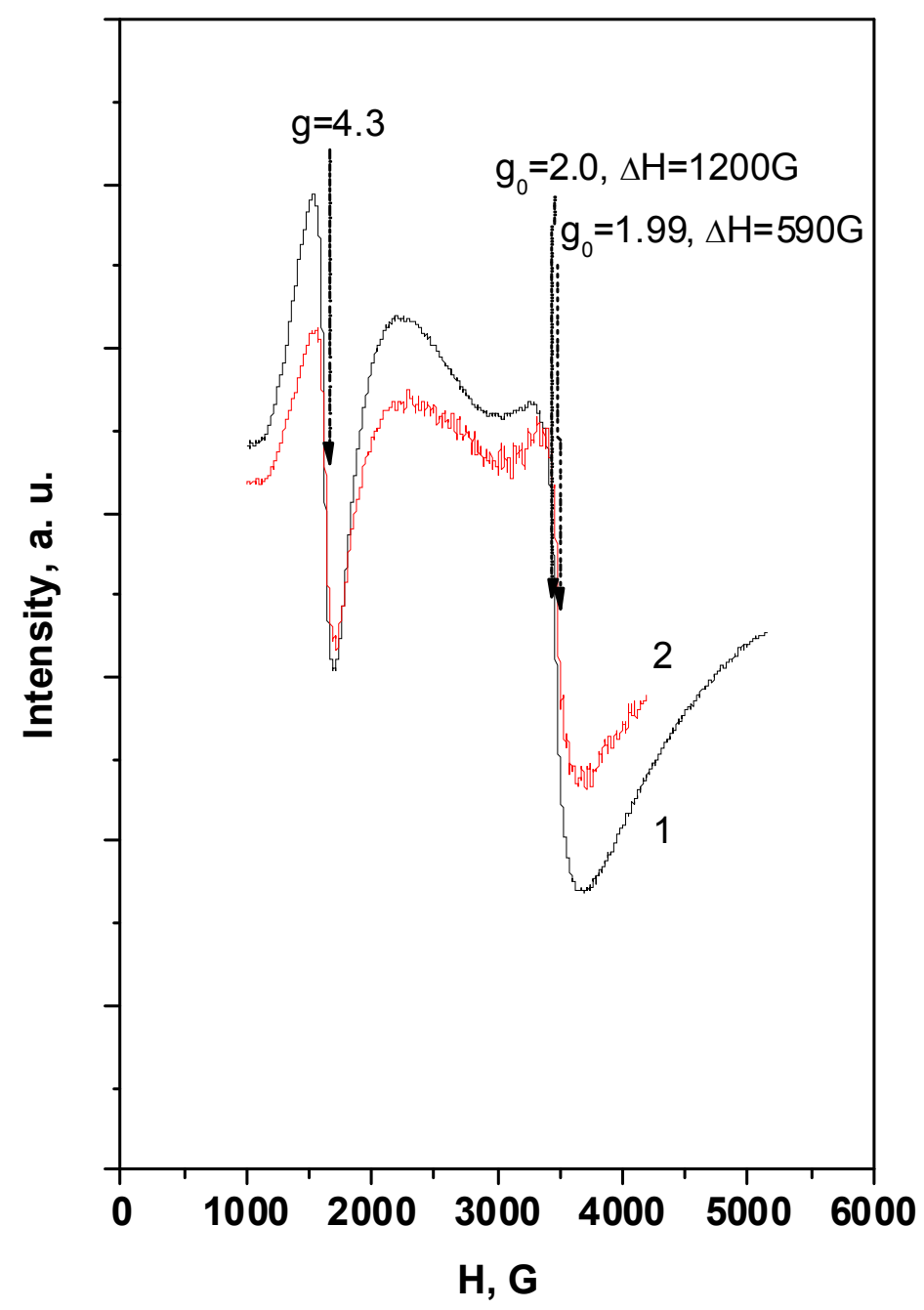

Figure 5c.

ESR spectra of Fe-silicalites Nanocrystals (A), Microcrystals (B) and Commercial Fe-ZSM5 (30) (C), before (1) and after activation in oxalic acid (2). Spectra were registered at $77 \mathrm{~K}$. 


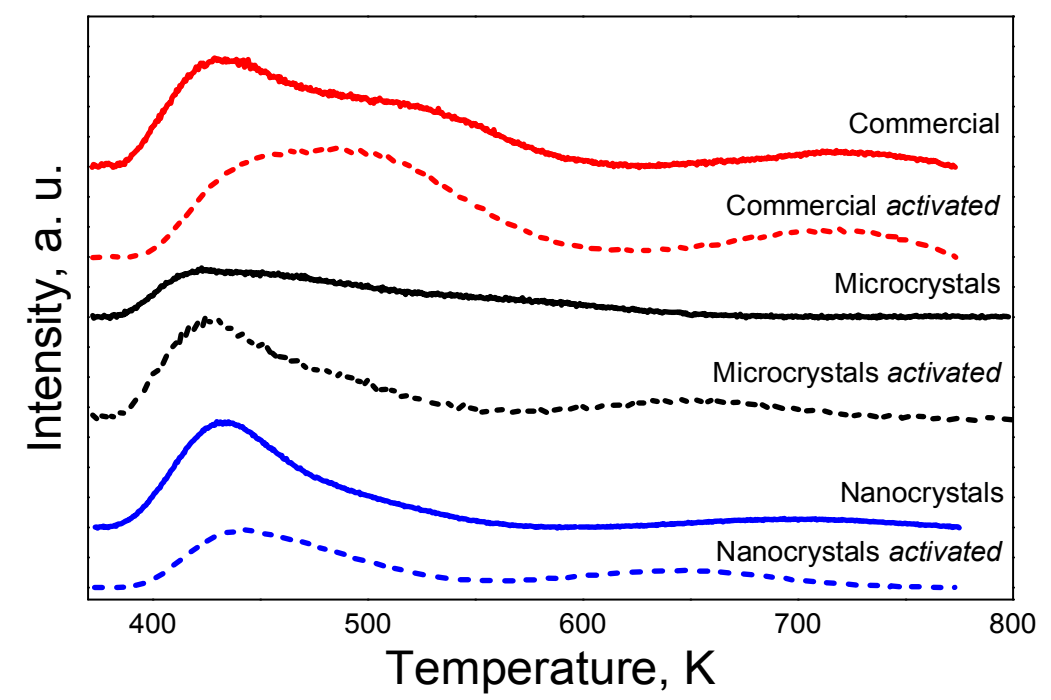

Figure 6.

Ammonia TPD profiles of Fe-silicalites and Commercial Fe-ZSM-5. 
a

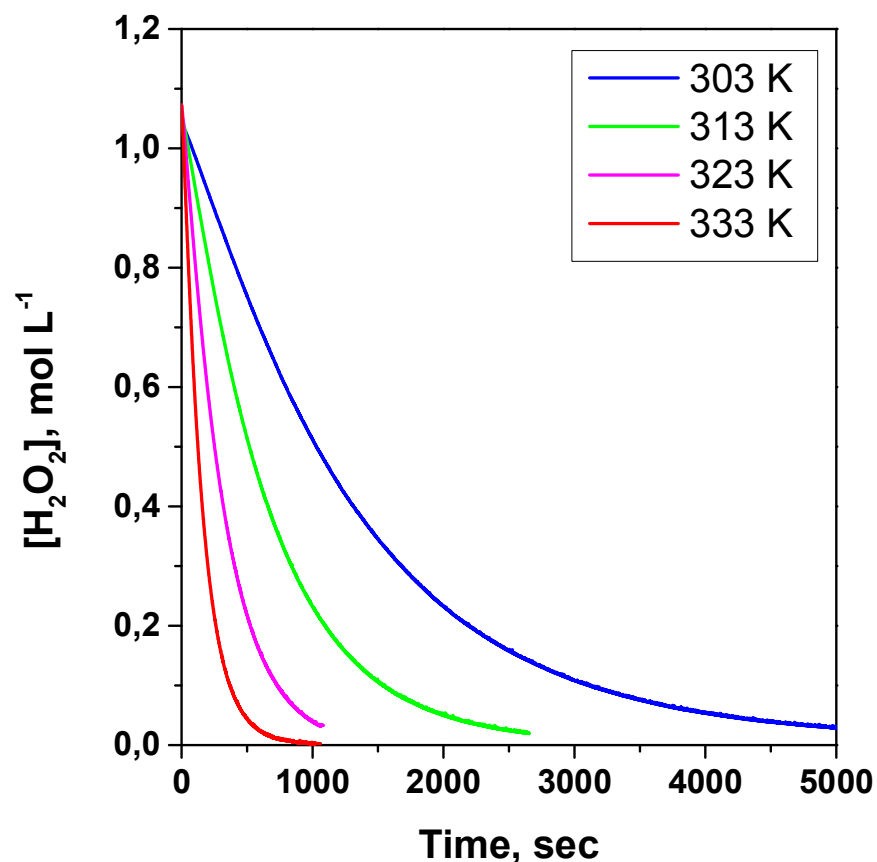

$\mathrm{b}$

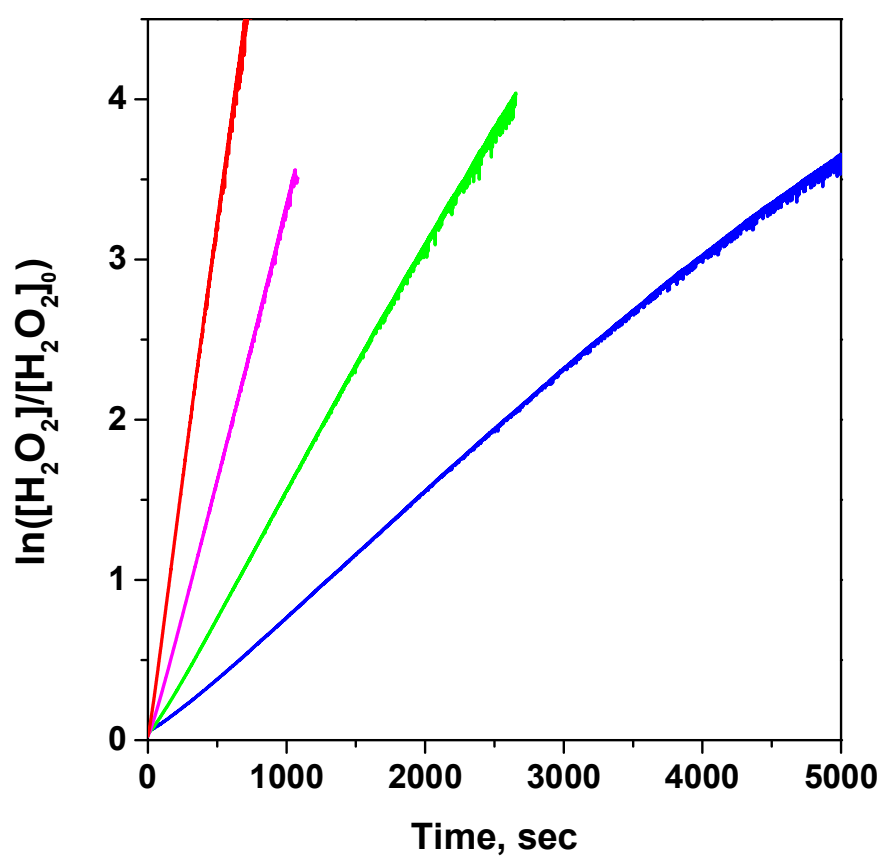

Figure 7.

Kinetics of $\mathrm{H}_{2} \mathrm{O}_{2}$ decomposition over activated commercial catalyst (a) and their anamorphoses in first order coordinates (и). 


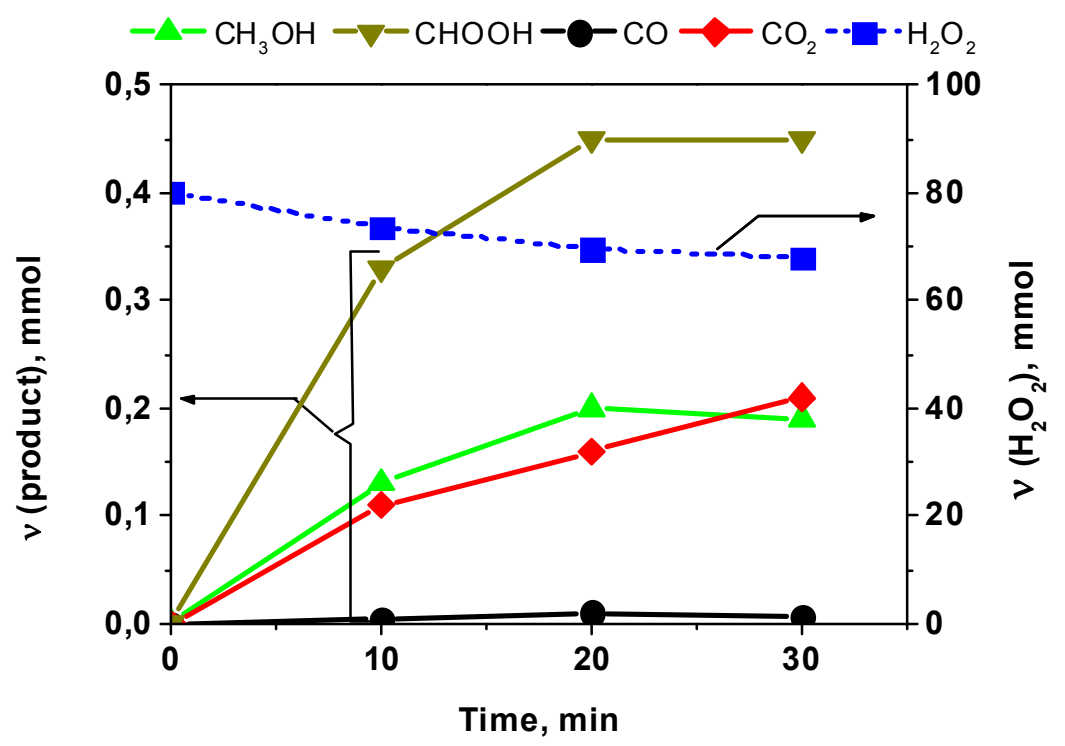

\section{Figure 8.}

Kinetics of the products evolution and the $\mathrm{H}_{2} \mathrm{O}_{2}$ destruction over Microcrystals activated. Reaction conditions: $323 \mathrm{~K}, 30$ bar, $30 \mathrm{~min}, 1 \mathrm{M} \mathrm{H}_{2} \mathrm{O}_{2}, 2.7 \mathrm{~g} \cdot \mathrm{L}-1$ catalyst, $\mathrm{pH}_{\text {initial }}$ 3.5; v(product) are molar quantities of the reaction products, $v\left(\mathrm{H}_{2} \mathrm{O}_{2}\right)$ are molar quantities of hydrogen peroxide in the sample.

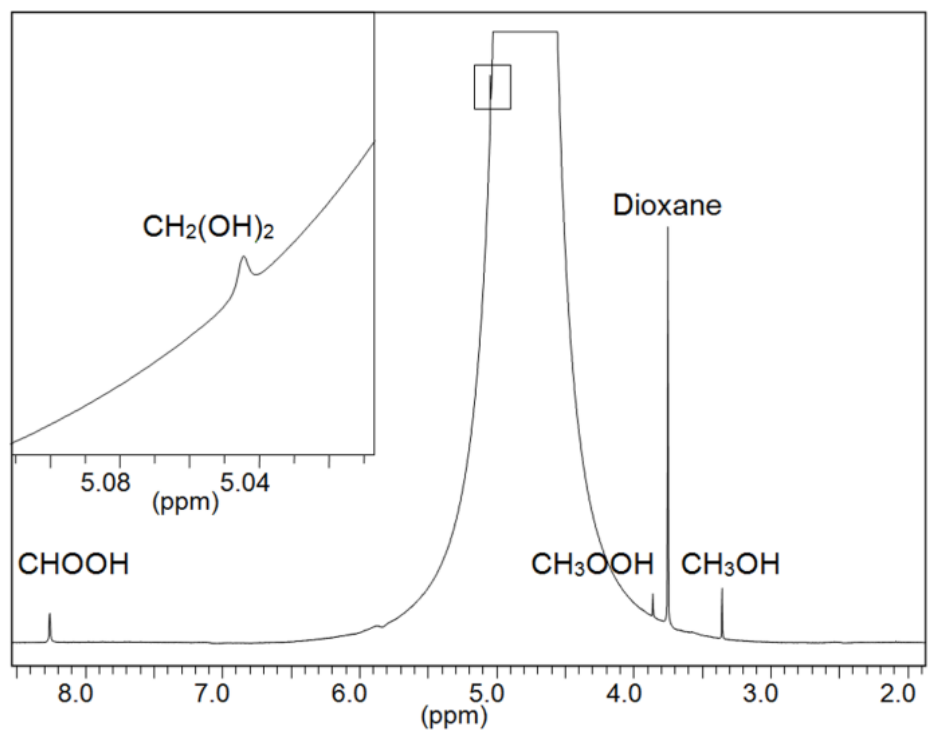

Figure 9.

${ }^{1} \mathrm{H}-\mathrm{NMR}$ spectra for reaction solution of oxidation of methane over Microcrystals activated. 


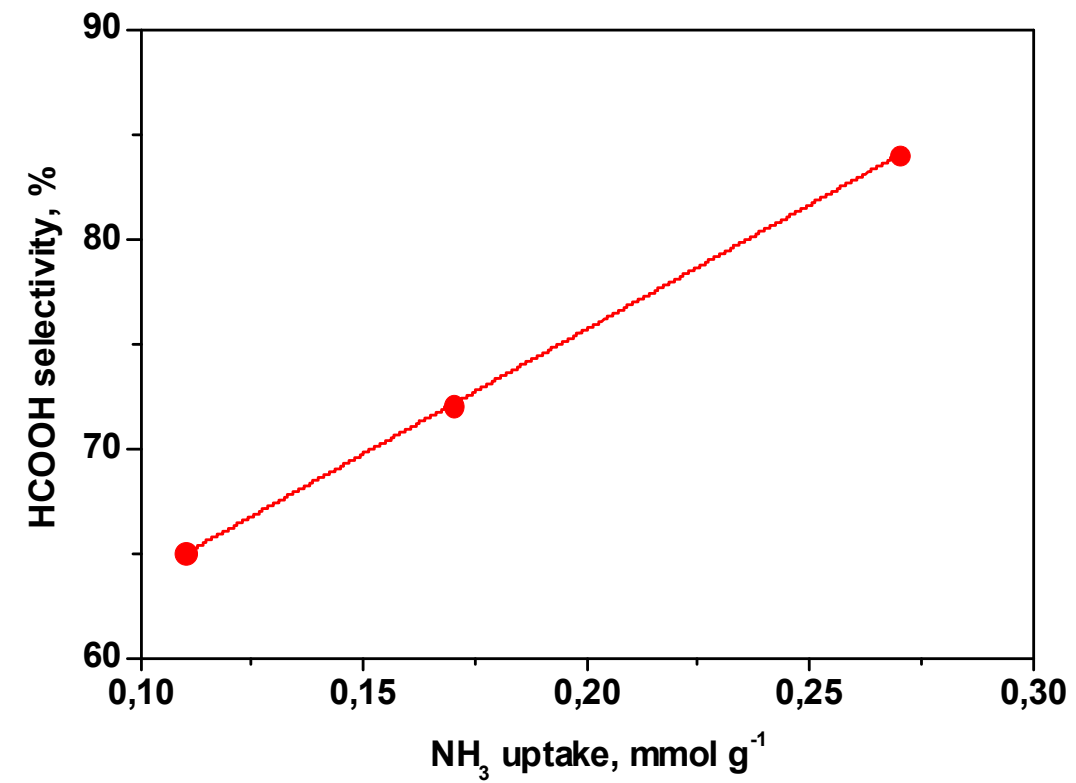

Figure 10.

The dependence of the selectivity to $\mathrm{HCOOH}$ on the acidity of the activated samples. 